\title{
Development, characterization and first deployment of an improved online reactive oxygen species analyzer
}

\author{
Jun Zhou ${ }^{1}$, Emily A. Bruns ${ }^{1}$, Peter Zotter ${ }^{2}$, Giulia Stefenelli ${ }^{1}$, André S. H. Prévôt ${ }^{1}$, Urs Baltensperger ${ }^{1}$, \\ Imad El-Haddad $^{1}$, and Josef Dommen ${ }^{1}$ \\ ${ }^{1}$ Paul Scherrer Institute, Laboratory of Atmospheric Chemistry, 5232 Villigen PSI, Switzerland \\ ${ }^{2}$ Lucerne University of Applied Sciences and Arts, School of Engineering and Architecture, CC Thermal \\ Energy Systems and Technology, Bioenergy Research, 6048 Horw, Switzerland
}

Correspondence: Josef Dommen (josef.dommen@psi.ch)

Received: 22 May 2017 - Discussion started: 29 May 2017

Revised: 30 October 2017 - Accepted: 6 November 2017 - Published: 9 January 2018

\begin{abstract}
Inhalation of atmospheric particles is linked to human diseases. Reactive oxygen species (ROS) present in these atmospheric aerosols may play an important role. However, the ROS content in aerosols and their formation pathways are still largely unknown. Here, we have developed an online and offline ROS analyzer using a $2^{\prime}, 7^{\prime}$ dichlorofluorescin (DCFH) based assay. The ROS analyzer was calibrated with $\mathrm{H}_{2} \mathrm{O}_{2}$ and its sensitivity was characterized using a suite of model organic compounds. The instrument detection limit determined as 3 times the noise is $1.3 \mathrm{nmol} \mathrm{L}^{-1}$ for offline analysis and $2 \mathrm{nmol} \mathrm{m}^{-3}$ of sampled air when the instrument is operated online at a fluorescence response time of approximately $8 \mathrm{~min}$, while the offline method detection limit is $18 \mathrm{nmol} \mathrm{L}^{-1}$. Potential interferences from gas-phase $\mathrm{O}_{3}$ and $\mathrm{NO}_{2}$ as well as matrix effects of particulate $\mathrm{SO}_{4}^{2-}$ and $\mathrm{NO}_{3}^{-}$were tested, but not observed. $\mathrm{Fe}^{3+}$ had no influence on the ROS signal, while soluble $\mathrm{Fe}^{2+}$ reduced it if present at high concentrations in the extracts. Both online and offline methods were applied to identify the ROS content of different aerosol types, i.e., ambient aerosols as well as fresh and aged aerosols from wood combustion emissions. The stability of the ROS was assessed by comparing the ROS concentration measured by the same instrumentation online in situ with offline measurements. We also analyzed the evolution of ROS in specific samples by conducting the analysis after storage times of up to 4 months. The ROS were observed to decay with increasing storage duration. From their decay behavior, ROS in secondary organic aerosol (SOA) can be separated into short- and long-lived fractions. The half-life of the short-
\end{abstract}

lived fraction was $1.7 \pm 0.4 \mathrm{~h}$, while the half-life of the longlived fraction could not be determined with our uncertainties. All these measurements showed consistently that on average $60 \pm 20 \%$ of the ROS were very reactive and disappeared during the filter storage time. This demonstrates the importance of a fast online measurement of ROS.

\section{Introduction}

Aerosol particles have negative effects on human health (Pope and Dockery, 2006), with an estimated 3\% of cardiopulmonary and $5 \%$ of lung cancer deaths attributable to particulate matter (PM) globally (WHO, 2013). One of the important pathways leading to deleterious impacts on health is believed to be induced oxidative stress by the generation of reactive oxygen species (ROS), through the interaction of particulate matter with the human lung (Donaldson et al., 2002). Reactive oxygen species denote chemically reactive molecules containing oxygen (e.g., radicals, oxygen ions and peroxides including the $\mathrm{OH}$ radical, the $\mathrm{O}_{2}^{-}$radical, $\mathrm{H}_{2} \mathrm{O}_{2}$ or organic peroxides) (Fuller et al., 2014; Sagai et al., 1993). As one of the main free radical sources generated in our body by various endogenous systems, ROS can adversely alter lipids, proteins and DNA structures, potentially leading to aging and numerous human diseases (Devasagayam et al., 2004). ROS exist both in the gas phase and in PM. ROS are either produced inside the human body through generation by the inhaled PM (e.g., by transition metals) in vivo (endogenous ROS) or by transportation into the lungs on respirable 
particles (exogenous ROS) (Zhao and Hopke, 2012). While gas-phase ROS are most likely removed in the upper mucus membranes through diffusion (Kao and Wang, 2002), ROS associated with fine particles can penetrate deeply into the lungs, causing oxidative stress and cell damage. Understanding the mechanisms by which ROS are formed, evolve and decay in the atmosphere is therefore of utmost importance for mitigating their influence on human health (Khurshid et al., 2014).

Currently, many acellular assays exist for the determination of ROS quantities in particles, including dithiothreitol (DTT) (Fang et al., 2015) and 2',7'-dichlorofluorescin (DCFH) (Fuller et al., 2014; King and Weber, 2013; Wang et al., 2011). The DCFH assay is one of the most commonly used assays today. Accurate ROS quantification remains challenging because some ROS are highly reactive and are likely at least partially degraded prior to measurement when using offline techniques, which typically have delays of hours, days or weeks. Therefore, online techniques (through direct sampling into the liquid phase and measurement within a few minutes) are necessary for reliable ROS quantification (Wragg et al., 2016).

In this work, we developed and characterized a highly sensitive ROS analyzer which can be used either online or offline. The removing efficiency of interfering oxidizing trace gases of $\mathrm{O}_{3}$ and $\mathrm{NO}_{2}$ was tested, and the matrix effects of particulate $\mathrm{SO}_{4}^{2-}$ and $\mathrm{NO}_{3}^{-}$as well as transition metals were assessed. Results from the application of this online and offline methodology to laboratory measurements of wood combustion emissions and ambient measurements at an urban site in Bern (Switzerland) are presented. To assess the stability of ROS, online in situ measurements were compared with offline measurements using the same instrumentation, and the evolution of ROS on specific samples was evaluated by conducting the analysis after storage times of up to 4 months. The results are put into perspective for future ROS measurement strategies.

\section{Methods}

\subsection{ROS analyzer}

In our experiments, ROS were measured using a DCFH assay, which is commonly used for examining ROS generation at a cellular level but has also been used for determining the oxidation potential of PM as an acellular assay (Fuller et al., 2014; King and Weber, 2013; Perrone et al., 2016; Sauvain et al., 2013; Venkatachari et al., 2005, 2007). In this assay, the presence of oxidizing species is assessed from the rapid oxidation of DCFH to the fluorescent compound dichlorofluorescein (DCF) in the presence of horseradish peroxidase (HRP). The chemical reaction mechanism is shown in Fig. S1 in the Supplement.
A schematic of the online aerosol ROS analyzer is shown in Fig. 1. The analyzer is composed of three components: the aerosol collector, the reaction chamber and the fluorescence analyzer. The same setup without the aerosol collector was used for offline analysis (Fig. S2).

\subsubsection{Aerosol collection}

Particles were collected at a flow rate of $\sim 1.7 \mathrm{~L} \mathrm{~min}^{-1}$, using an aerosol collector, of which the main part is the mist chamber (Takeuchi et al., 2005). Before the aerosol collector, a honeycomb charcoal denuder of $10 \mathrm{~cm}$ length with $7 \mathrm{~mm}$ outer diameter ( $36 \%$ open area; $450 \mu \mathrm{m}$ channel width) was installed inside a stainless steel tube to remove $\mathrm{O}_{3}$, $\mathrm{NO}_{2}$ and organic vapors. The denuder was regenerated for at least $24 \mathrm{~h}$ at $250^{\circ} \mathrm{C}$ under a stream of $99.999 \% \mathrm{~N}_{2}$ before each experiment. By using at least two denuders, we were able to switch between them and to perform the experiments continuously. The Plexiglas aerosol collector had an approximate volume of $13.5 \mathrm{~cm}^{3}$. It consisted of an air inlet, a nebulizing nozzle inlet port for pure water injection, a mist chamber, a $2.5 \mathrm{~cm}$ diameter hydrophilic cellulose filter (Grade 497 circles, Schleicher \& Schuell Rundfilter) supported by a $5.0 \mu \mathrm{m}$ pore size hydrophobic membrane filter (Isopore membrane filters, TMTP series, Merck Millipore) to prevent the loss of the sample solution, an outlet to the vacuum pump and an exit for the water extracts (Fig. 1). The collection efficiency for water-soluble particles was determined by Takeuchi et al. (2005) to be $80 \%$ for $100 \mathrm{~nm}$ particles and higher than $97.7 \%$ for particles $>280 \mathrm{~nm}$. Between the vacuum pump and the mist chamber, a flow controller protected by a water trap was installed. To stabilize the air sampling flow, an additional gas buffer volume was introduced before the pump. The $1.7 \mathrm{~L} \mathrm{~min}^{-1}$ air stream was mixed with oxygen-free ultra-pure water (OFUPW), which was continuously sprayed into the mist chamber with a flow rate of $0.3 \mathrm{~mL} \mathrm{~min}^{-1}$, where the aerosol particles were incorporated into the water droplets. The liquid containing the water-soluble fraction of the aerosol was continuously collected at the bottom of the aerosol collector at a flow rate of $0.3 \mathrm{~mL} \mathrm{~min}^{-1}$ and then mixed with the working solution (WS) at a flow rate of $0.4 \mathrm{~mL} \mathrm{~min}^{-1}$ for analysis. This resulted in a total flow rate of $0.7 \mathrm{~mL} \mathrm{~min}^{-1}$. Therefore, the measurement of ROS is continuous, which provides real-time measurement of ROS. OF-UPW was prepared by bubbling $99.999 \% \mathrm{~N}_{2}$ for $\sim 20$ min through Milli-Q water $\left(18.2 \mathrm{M} \Omega \mathrm{cm}\right.$ at $25^{\circ} \mathrm{C}$, total organic carbon $\left.<3 \mathrm{ppb}\right)$ to reduce the dissolved oxygen. The use of oxygen-free water reduced the instrument background by a factor of $\sim 2$ compared to normal ultra-pure water.

In most studies using the DCFH assay, aerosol samples were extracted either in a DCFH-HRP (King and Weber, 2013) or an HRP solution (Fuller et al., 2014). We tested the auto-oxidation of the working solution containing both HRP and DCFH. By mixing only OF-UPW with the HRP- 


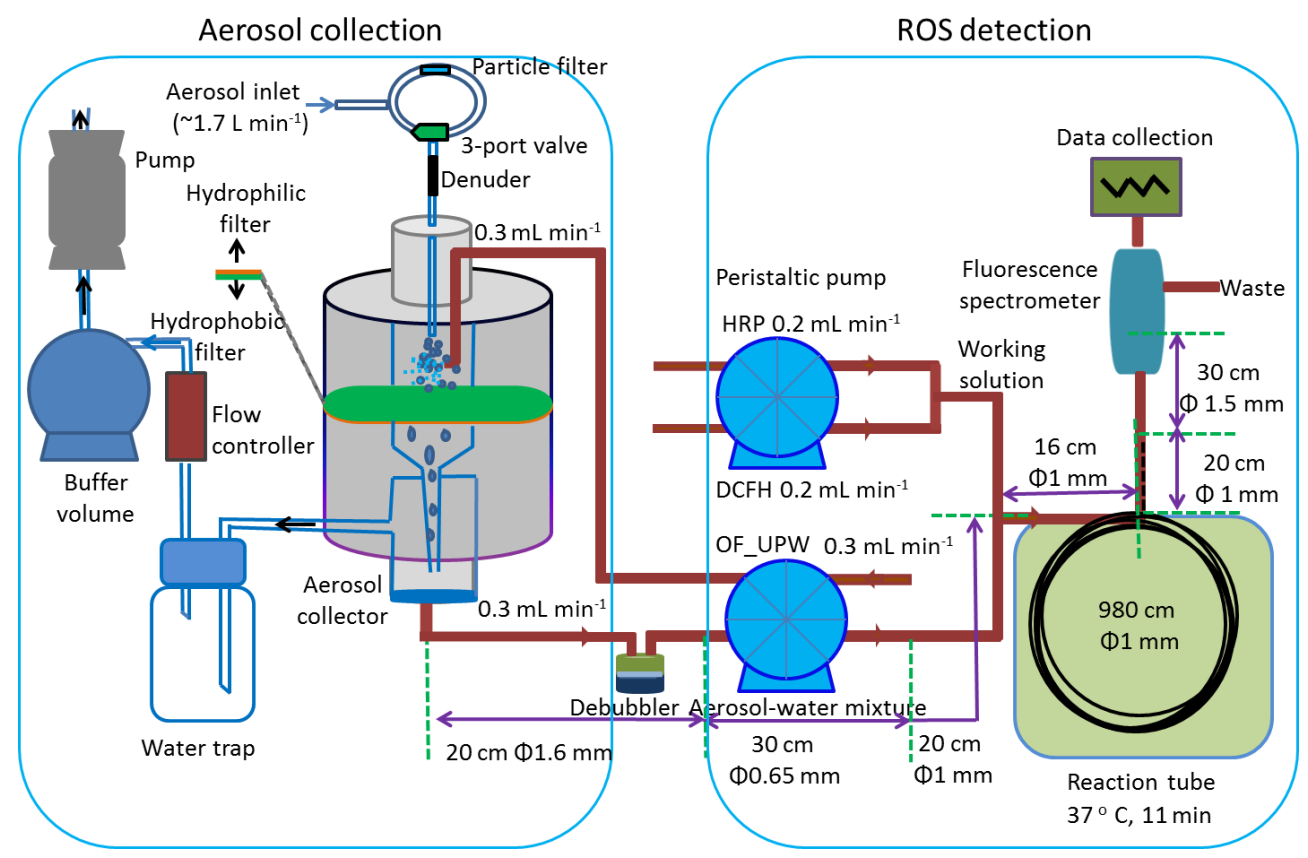

Figure 1. An overview of the online ROS analyzer. OF-UPW refers to oxygen-free ultra-pure water. The same setup without the aerosol collector was used for the offline analysis (shown in Fig. S2).

DCFH working solution, the signal, which is actually the background, increased with a rate of $0.9 \% \mathrm{~h}^{-1}$. This means that there is a slow reaction with the dissolved oxygen consuming the DCFH consequently shortening the lifespan of the HRP-DCFH solution. When the sample is extracted online with the HRP solution as in Fuller et al. (2014), the HRP needs to go through the aerosol collector, where contaminants adsorbed on the hydrophilic and hydrophobic filters or the oxygen in the mist chamber might react with HRP and then oxidize DCFH as described by Berglund et al. (2002) and modified by Fuller et al. (2014). Therefore, we used only OF-UPW to extract the aerosol samples. The DCFH and HRP reagents were kept separate and were only mixed together right before the aerosol aqueous extract was added.

\subsubsection{ROS detection}

The aerosol aqueous extract collected from the aerosol collector was sampled by a peristaltic pump through a "TRACE TRAP bubble trap" debubbler (TRACE Analytics GmbH, Germany), which effectively removed gas bubbles in the sample liquid without introducing a large dead liquid volume and signal broadening. At the same time, the two reagent solutions DCFH and HRP were drawn by another peristaltic pump and mixed to form the WS. The aerosol aqueous extract was then mixed with the WS and pumped through a reaction coil consisting of polyetheretherketone (PEEK) tubing (9.8 m length, $1.6 \mathrm{~mm}$ OD, $1.0 \mathrm{~mm}$ ID, Kinesis $\mathrm{GmbH}$ ) in an air-ventilated temperature controlled housing held at $37^{\circ} \mathrm{C}$. The obtained solution was then analyzed using a spectrofluo- rometer with excitation and emission wavelengths of 470 and $520 \mathrm{~nm}$, respectively. All transparent parts of the system were wrapped with aluminum foil to avoid the photooxidation of the DCFH.

\subsubsection{Offline analysis}

The instrument was also used for offline analysis of filters (Fig. S2). In general, we extracted a filter punch of $14 \mathrm{~mm} \varnothing$ of the filter area in $10 \mathrm{~mL}$ of OF-UPW for $15 \mathrm{~min}$ at $30^{\circ} \mathrm{C}$. However, the filter area and/or the volume of the OF-UPW was sometimes adjusted to keep the extracted ROS concentration in the measurement range of the instrument. The vial was then vortexed (Vortex Genie 2, Bender \& Holbein AG, Switzerland) for $1 \mathrm{~min}$ to ensure homogeneity and filtered through a $0.45 \mu \mathrm{m}$ nylon membrane syringe filter (Infochroma, Switzerland). The extract was then injected into the ROS analyzer in the same way as the online method with a flow rate of $0.3 \mathrm{~mL} \mathrm{~min}^{-1}$ and mixed with the working solution at a rate of $0.4 \mathrm{~mL} \mathrm{~min}^{-1}$ for analysis. Thus, the mixture of the flows was the same for online and offline analysis.

Often filters are extracted in an ultrasonic bath. However, recent studies suggest that sonication of pure water with dissolved air may create hydroxyl radicals due to the high temperature and pressure created by the collapse of bubbles formed by cavitation, which then form $\mathrm{H}_{2} \mathrm{O}_{2}$ or react with sample species (Mark et al., 1998; Miljevic et al., 2014). This was also demonstrated by Fuller et al. (2014), who showed the formation of $0.08 \mathrm{nmol} \mathrm{m}^{-3}$ ROS by the sonication of pure water. These effects have also been confirmed in our 
laboratory by analyzing filters collected at an urban site in Milan extracted with and without sonication (Perrone et al., 2016). Therefore, sonication was not used for filter extraction during offline measurements.

\subsubsection{Working solution}

The stability of the WS is an important factor. Since HRP can catalyze the reaction of DCFH with dissolved oxygen in the phosphate buffer (Berglund et al., 2002; Huang et al., 2016; Rota et al., 1999a, b), the phosphate buffer solution (PBS, $1 \mathrm{M}$, Sigma-Aldrich, USA) was degassed with $99.999 \% \mathrm{~N}_{2}$ for $\sim 20 \mathrm{~min}$. Furthermore, the two reagents DCFH and HRP were prepared separately as follows:

For the DCFH reagent, $2^{\prime}, 7^{\prime}$-dichlorofluorescin diacetate (DCFH-DA) (0.61 mL, Sigma-Aldrich, USA) stock solution $(0.001 \mathrm{M})$ was mixed with $\mathrm{NaOH}(10 \mathrm{~mL}, 0.001 \mathrm{M}$, SigmaAldrich, USA) for $30 \mathrm{~min}$ under dark conditions to initiate a deacetylation at room temperature. Then PBS $(25 \mathrm{~mL})$ was added to set the solution $\mathrm{pH}$ at 7.2 and neutralize any remaining $\mathrm{NaOH}$. This produces the fluorescent probe DCFH, referred to as WS-A hereafter.

For the HRP reagent, horseradish peroxidase $(0.44 \mathrm{mg}$, HRP, type II, Sigma-Aldrich, USA) was dissolved in PBS $(35.6 \mathrm{~mL})$ to generate a stock solution of 2 units $\mathrm{mL}^{-1}$, which is referred to as WS-B afterwards.

WS-A and WS-B were then degassed for $20 \mathrm{~min}$ and only mixed together during the analysis at a $1: 1$ ratio. The final WS was $17.6 \mu \mathrm{M}$ of DCFH and 1 unit $\mathrm{mL}^{-1}$ of HRP. This WS and the applied procedures provided the following advantages compared to previous analyzers using the same assay:

1. The $\mathrm{pH}$ of the WS was maintained constant at 7.2, which resulted in a stable background.

2. HRP and DCFH were prepared separately and mixed together only right before the combination with the sample solution. This reduced auto-oxidation and decreased the instrument background signal.

3. Both working solutions were stored at $\sim 4^{\circ} \mathrm{C}$ and could be used for up to 1 week, while a mixed DCFH-HRP is not stable for more than 1 day.

\subsubsection{Calibration}

The instrument was calibrated with known concentrations of $\mathrm{H}_{2} \mathrm{O}_{2}$ solutions. Standards were prepared from a concentrated solution of hydrogen peroxide $\left(\mathrm{H}_{2} \mathrm{O}_{2}\right.$, solution, $3 \mathrm{wt} \%$ in water, Sigma-Aldrich). Calibration solutions of different concentrations were generated by diluting different amounts of a stock solution with OF-UPW. The blank values were obtained by measuring OF-UPW alone.
For the online operation mode, $\mathrm{H}_{2} \mathrm{O}_{2}$ equivalent particulate ROS concentrations $c$ were determined as follows:

$c\left(\frac{\mathrm{nmol}}{\mathrm{m}^{3}}\right)=\left(\frac{I-b}{a}\right)\left(\frac{V_{i}}{Q_{\mathrm{c}}}\right)$,

where $I$ is the fluorescence signal (volt), $b$ is the calibration intercept from the linear regression fit, $a$ is the calibration slope from the linear regression fit $\left(\operatorname{Volt~nM}^{-1}\right), V_{i}$ is the OFUPW flow into the mist chamber $\left(\mathrm{mL} \mathrm{min}^{-1}\right)$, and $Q_{\mathrm{c}}$ is the air flow through the aerosol collector $\left(\mathrm{L} \mathrm{min}^{-1}\right.$, at ambient temperature and pressure). For the offline operation mode, particulate ROS concentrations in air were determined as follows:

$c\left(\frac{\mathrm{nmol}}{\mathrm{m}^{3}}\right)=\left(\frac{I-b}{a}\right)\left(\frac{V_{i}}{Q_{\mathrm{c}}}\right)\left(\frac{A_{\text {filter }}}{A_{\text {punch }}}\right)$,

where $V_{i}$ is the volume of OF-UPW for filter extraction (mL), $Q_{\mathrm{c}}$ is the total air volume drawn through the filter (L, at ambient temperature and pressure) and $\frac{A_{\text {filter }}}{A_{\text {punch }}}$ is the ratio of the area of the entire filter to the area of the filter punch.

The instrument background of the online operation mode was always higher than that of the offline operation mode, which may be due to the uptake of oxygen in the mist chamber in the online system.

\subsection{Instrument maintenance and portability}

The instrument can be easily disassembled and rebuilt to be used in both laboratory and field campaigns. The instrument is not yet fully automatized. The following manual operations are required: (1) calibration; (2) replacing the hydrophilic and hydrophobic filters in the aerosol collector and the denuder every 2-3 days during ambient measurements while in laboratory experiments, we exchanged the denuder for each laboratory experiment $(\sim 5 \mathrm{~h})$ to be on the safe side; (3) regularly switching the air inlet channel to the particlefree mode (ROS blank) and checking the air flow during the measurement (before the experiment, during the experiment and after the experiment) to insure that the air sample flow was constant at $1.7 \mathrm{~L} \mathrm{~min}^{-1}$; (4) cleaning of the ROS analyzer with $1 \mathrm{M} \mathrm{H}_{2} \mathrm{SO}_{4}$ for $\sim 12 \mathrm{~h}$ every 2 weeks to remove contaminations in the system; (5) replacing all the tubes used in the system every 6 months.

\subsection{Instrument testing}

In order to assess the performance of the ROS analyzer several tests were performed, including the following:

1. The influence of the reaction time and the instrument detection limit, repeatability and reproducibility (Sect. 3.1.1 and 3.1.2).

2. Response of the DCFH assay to selected components with expected capability to act as reactive oxygen species (Sect. 3.1.2 and 3.3.2). 

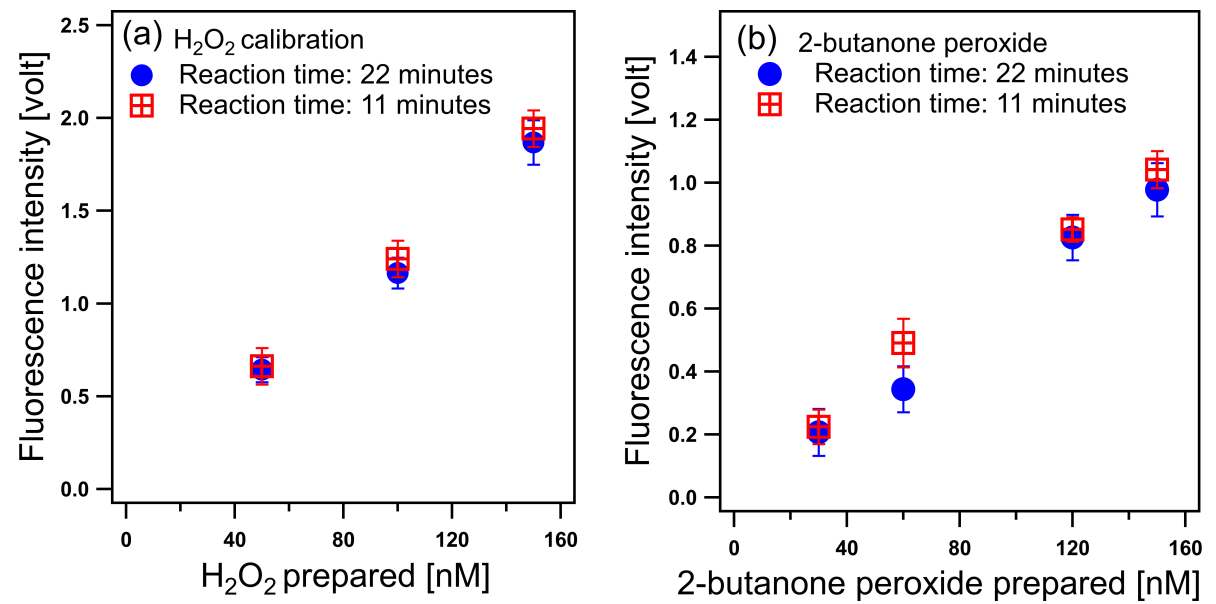

Figure 2. Fluorescence responses to (a) $\mathrm{H}_{2} \mathrm{O}_{2}$ and (b) 2-butanone peroxide (2-hydroperoxy-2-(2-hydroperoxybutan-2-ylperoxy)butane) under different reaction times. Error bars represent the propagation of the uncertainty $\left(\delta=\sqrt{\delta_{1}^{2}+\delta_{2}^{2}}\right.$, with $\delta_{1}$ representing the standard deviation of the instrument background signal of that experiment day and $\delta_{2}$ the standard deviation of the sample signal).

3. Assessment of the interference from selected abundant gas-phase and PM constituents (Sect. 3.2 and 3.3) on the ROS signals.

4. Verification of the instrument performance using genuine aerosol samples. Measurement of the ROS content in ambient aerosols was performed offline using filter samples collected in Milan (Italy), San Vittore (Switzerland) and Bern (Switzerland) and online using the developed ROS analyzer in Bern (Switzerland) (Sect. 3.1.3, 3.4.1 and 3.4.2). These samples include total suspended particulate matter (TSP), $\mathrm{PM}_{2.5}$ and $\mathrm{PM}_{10}$ (particulate matter with a diameter smaller than 2.5 and $10 \mu \mathrm{m}$, respectively). Laboratory samples were also measured, including online and offline ROS measurements of fresh and aged aerosols from wood combustion emissions, by using two different aging tools, a potential aerosol mass (PAM) chamber and a smog chamber (SC). Tests aimed at the verification of the instrument linearity, the assessment of matrix effects, the comparison of online and offline ROS measurements and the examination of the ROS degradation.

\section{Results}

\subsection{Instrument performance}

\subsubsection{Reaction time and detection limit}

The reaction time between the WS and the aerosol sample is an important parameter. Here, reaction times of 11 and $22 \mathrm{~min}$ were investigated by using different reaction tube lengths in the reaction chamber and followed by measurement of the fluorescence intensity resulting from the reaction of $\mathrm{H}_{2} \mathrm{O}_{2}$ (Fig. 2a) and 2-hydroperoxy-2-(2hydroperoxybutan-2-ylperoxy)butane (Fig. 2b) with the WS. The 22 min reaction time resulted in a $35 \%$ higher instrumental background signal than the 11 min reaction time. However, the same incremental increase in fluorescence intensity was found for the sample solutions of both $\mathrm{H}_{2} \mathrm{O}_{2}$ and the organic peroxide at the two reaction times, resulting in the same detection sensitivity. Here the detection sensitivity $\left(\mathrm{VnM}^{-1}\right)$ is defined as the ratio between the change in the output signal (in volt) to the corresponding change in the peroxide concentration (in $\mathrm{nM}$ ). This suggest that the fluorescence response is unaffected by the reaction time in the investigated range, even for compounds protected by tertbutyl groups. Therefore, a reaction of $11 \mathrm{~min}$ seems to be sufficient to reduce all peroxides that can react with DCFH and we consequently used this reaction time for the further experiments. The residence and response time of the sample in the instrument were measured to be approximately 19 and $8 \mathrm{~min}$, respectively. The former was determined as the time from the injection of an $\mathrm{H}_{2} \mathrm{O}_{2}$ solution to the time the fluorescence signal started to increase, while the response time corresponds to the rise time of the fluorescence signal from 10 to $90 \%$ of the full signal.

Under normal instrument operation conditions, an instrument limit of detection (LOD) of $2 \mathrm{nmol} \mathrm{m}^{-3}$ of sampled ambient air was determined for the online methodology. This was obtained as 3 times the standard deviation when a particle filter was placed in the sampling line upstream of the analyzer (Long and Winefordner, 1983). For the offline methodology, which is used for the instrument testing, it is important to define two different parameters: the instrument LOD and 


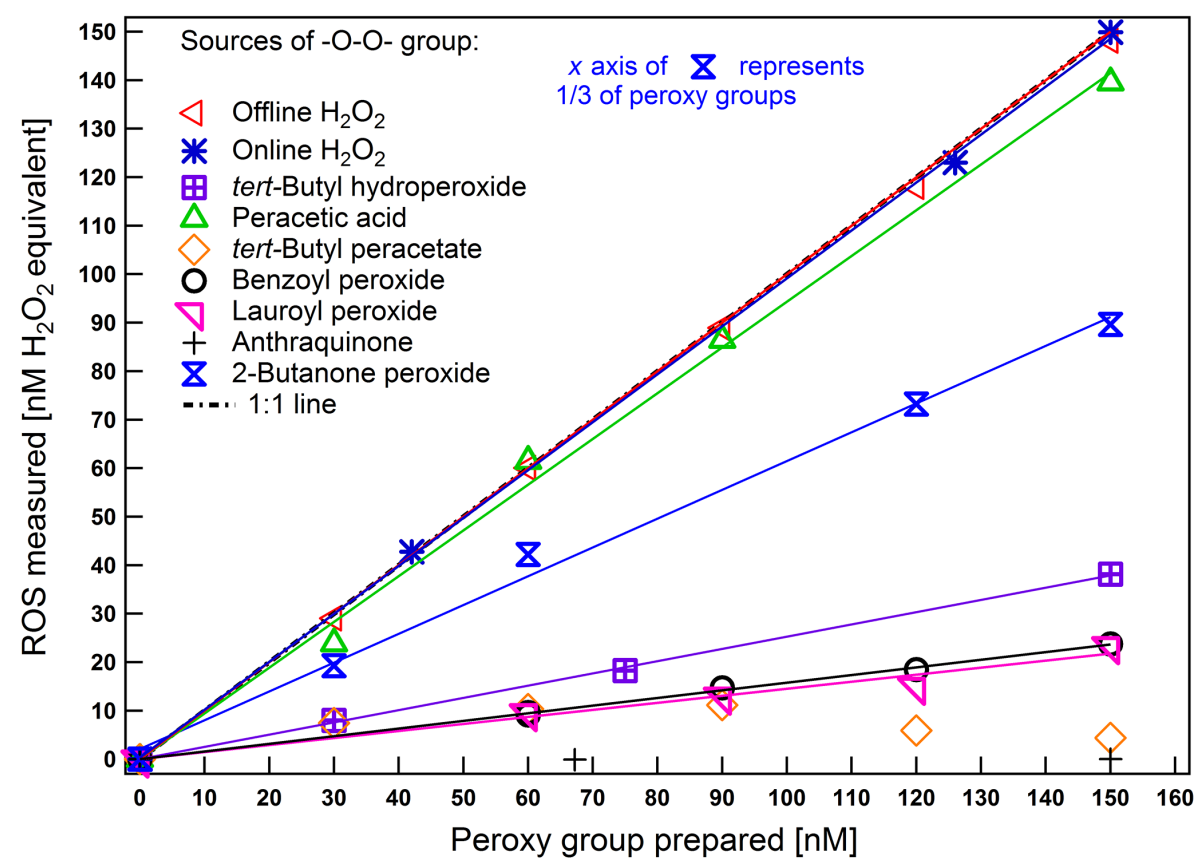

Figure 3. Calibration curves of $\mathrm{H}_{2} \mathrm{O}_{2}$ and response of selected compounds (with the instrument used in the offline mode unless indicated otherwise). Linear fits are shown for different peroxides and other compounds of interest in the concentration range of 0 to $150 \mathrm{nM}$. The correlation coefficients $R^{2}$ were 0.99 , except for lauroyl peroxide $\left(R^{2}=0.91\right)$.

the method LOD. The instrument LOD was $1.3 \mathrm{nmol} \mathrm{L}^{-1}$, determined as 3 times the standard deviation of the background when OF-UPW was injected into the sampling line. The method LOD was determined based on the reproducibility of the instrument background and the filter blanks. The reproducibility of the background was assessed by injecting different batches of OF-UPW several times. The value of $9 \mathrm{nmol} \mathrm{L}^{-1}$, equivalent to 3 times the standard deviation of the resulting signals, was then used as a measure of this reproducibility and the offline method LOD. A similar LOD value was obtained as 3 times the standard deviation of the measurements of extracts of fractions of four different blank filters $\left(2.2 \mathrm{~cm}^{2}\right.$ ) and was equal to $13 \mathrm{nmol} \mathrm{L}^{-1}$ (for both quartz and Teflon filters). We note that the average signal of these blanks was $25 \mathrm{nmol} \mathrm{L}^{-1}$, which was subtracted from the signals measured when extracts of aerosol samples (with equivalent filter area) were injected.

\subsubsection{Repeatability, reproducibility and response to selected model compounds}

We assessed the instrument performance based on three repeated calibrations with $0,30,50,100$ and $150 \mathrm{nM} \mathrm{H}_{2} \mathrm{O}_{2}$ (Fig. S3). The instrument accuracy in determining the ROS concentration was found to be $3 \%(n=15)$, based on the standard deviation of the slope of the linear fit. The precision (repeatability) of the preparation of the $\mathrm{H}_{2} \mathrm{O}_{2}$ solution used for the calibration, estimated at different $\mathrm{H}_{2} \mathrm{O}_{2}$ concentrations based on the fit prediction interval, was 25,10 and
$5 \%$ at 30,70 and $150 \mathrm{nM}$, respectively. Based on this, the uncertainty of $\mathrm{H}_{2} \mathrm{O}_{2}$ at extremely low concentrations would be $18 \mathrm{nM}$. This is larger than the method LOD determined above from the OF-UPW and blank filters. We consider the largest of these uncertainties (i.e., $18 \mathrm{nM}$ ) as our final method LOD.

The instrument reproducibility was assessed based on the variation in the instrument sensitivity (in $\mathrm{VnM}^{-1}$ ). In practice, we calculated the standard deviation of the response of 10 repeated measurements of known concentrations of $\mathrm{H}_{2} \mathrm{O}_{2}$ at different days using different WS. This reproducibility was found to be $\sim 40 \%(1 \sigma)$, which is much higher than the instrument precision, possibly due to the solution preparation and instrument operation conditions. Consequently, a calibration was always carried out at the beginning or at the end of each measurement series.

While the characterization tests discussed above were carried out using the offline mode, we obtained similar results when the instrument was used in the online mode. Figure 3 shows that a similar linear relationship was obtained between the instrument response and the $\mathrm{H}_{2} \mathrm{O}_{2}$ concentration for the online (blue stars) and offline (red triangles) modes, resulting in statistically similar sensitivities ( $t$ test, $p$ value $=0.93$ ) This provides confidence in using the calibration and tests performed offline to predict online concentrations.

We also tested the response of the instrument to components expected to exhibit the capability to act as reactive oxygen species, including peracetic acid (PAA; 39\% in acetic 
Table 1. Model organic peroxides used in this study.

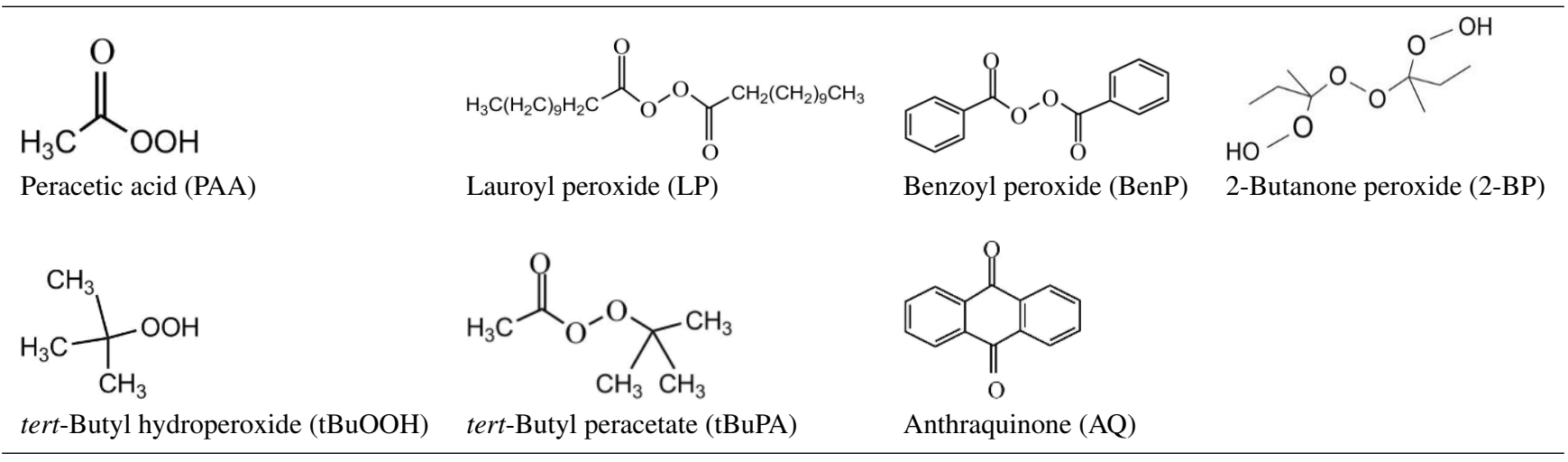

acid, $\leq 6 \% \mathrm{H}_{2} \mathrm{O}_{2}$, Sigma-Aldrich), tert-butyl hydroperoxide (tBuOOH; Luperox ${ }^{\circledR}$ TBH70X, 70 wt. \% in water, SigmaAldrich), benzoyl peroxide (BenP; Luperox ${ }^{\circledR}$ A75, 75\%, remainder water, Sigma-Aldrich), lauroyl peroxide (LP; Luperox $^{\circledR}$ LP, $97 \%$, Sigma-Aldrich), tert-butyl peracetate (tBuPA; Luperox ${ }^{\circledR}$ 7M50, 50 wt. \% in aliphatic hydrocarbons, Sigma-Aldrich), anthraquinone (AQ; 97\%, SigmaAldrich) and 2-butanone peroxide (2-BP; Luperox ${ }^{\circledR}$ DHD9, 32 wt. \%, Sigma-Aldrich). Table 1 provides an overview of the chemical structures of these compounds. The watersoluble peroxides, i.e., $\mathrm{PAA}, \mathrm{tBuOOH}$ and $\mathrm{tBuPA}$, were dissolved in OF-UPW. The water insoluble compounds, i.e., BenP, LP and AQ, were dissolved in ethyl acetate $(99.8 \%$, Sigma-Aldrich) and then diluted (by a factor of $\sim 10000$ ) using OF-UPW.

Response curves of the selected compounds with an expected capability to act as reactive oxygen species compared to $\mathrm{H}_{2} \mathrm{O}_{2}$ are shown in Fig. 3. PAA showed a linear fluorescence intensity response similar to $\mathrm{H}_{2} \mathrm{O}_{2}$ (relative sensitivity $s=93 \%$ ). In contrast, AQ and organic peroxides like tBuPA barely reacted. Low responses were observed for $\mathrm{tBuOOH}(s=25 \%)$, BenP $(s=16 \%)$ and LP $(s=15 \%)$, as well as for 2-BP, which includes three OO-function groups $(s=21 \%)$. The hydroperoxide groups in tBuPA, tBuOOH, BenP, LP and 2-BP are heavily protected by tert-butyl, phenyl and alkyl groups, which likely suppresses the reaction with DCFH. Less protected peroxides might be more reactive but such compounds are also less stable and therefore not usually commercially available. This indicates that, using a DCFH assay, the signal intensity of peroxides varies significantly depending on the peroxide molecular structure and that sterically hindered peroxides may contribute much less to the DCFH signal. Thus, we regard the ROS signal measured by the DCFH assay as a lower limit for the effective ROS content. Additionally, components known to induce redox cycling (e.g., metal ions and anthraquinone) do not seem to react with DCFH. Thus, we conclude that DCFH measures the capability of particle-borne compounds to act as reactive oxygen species rather than the potential of species to mediate ROS formation.

\subsubsection{Instrument performance in ambient and smog chamber measurements}

In order to evaluate the performance of the ROS analyzer in the field, two sets of experiments were conducted. In the first set, the instrument was operated in the offline mode using filter samples collected at two different sites: (a) a site influenced by traffic emissions in Milan (northern Italy), where quartz filters were sampled during October 2013 (Perrone et al., 2016); and (b) a rural site in San Vittore (southern Switzerland in an Alpine valley) influenced by biomass burning, where samples were collected during January 2013 (Daellenbach et al., 2017; Zotter et al., 2014). More details on the analysis of the samples can be found in the cited references. The samples from both sites were stored in the freezer at $-20{ }^{\circ} \mathrm{C}$ for 2 years before ROS analysis. A filter punch was dissolved in water and several sample solutions were prepared by consecutive dilutions. Figure 4 shows a linear relationship of the fluorescence response with decreasing particle mass concentration (based on the mass on the filter punch and assuming $100 \%$ water solubility) for both samples, where equivalent $\mathrm{H}_{2} \mathrm{O}_{2}$ concentrations span a wide range, which confirms the instrument linearity. The different slopes between these two data sets might be due to the different emission sources (traffic in Milan and wood combustion in San Vittore) at these two locations (see Perrone et al., 2016; Zotter et al., 2014).

The second set of experiments was performed at the PSI smog chamber. Beechwood logs were combusted in a residential wood burner (Avant, 2009, Attika), following the procedure described in Bruns et al. (2016, 2017). The resulting emissions were sampled from the chimney through a heated line $(473 \mathrm{~K})$, diluted by a factor of $\sim 8-10$ using an ejector diluter (473 K; DI-1000, Dekati Ltd.), and injected into the smog chamber. Emissions were only sampled during the stable flaming phase for 11-21 min and the total dilution fac- 


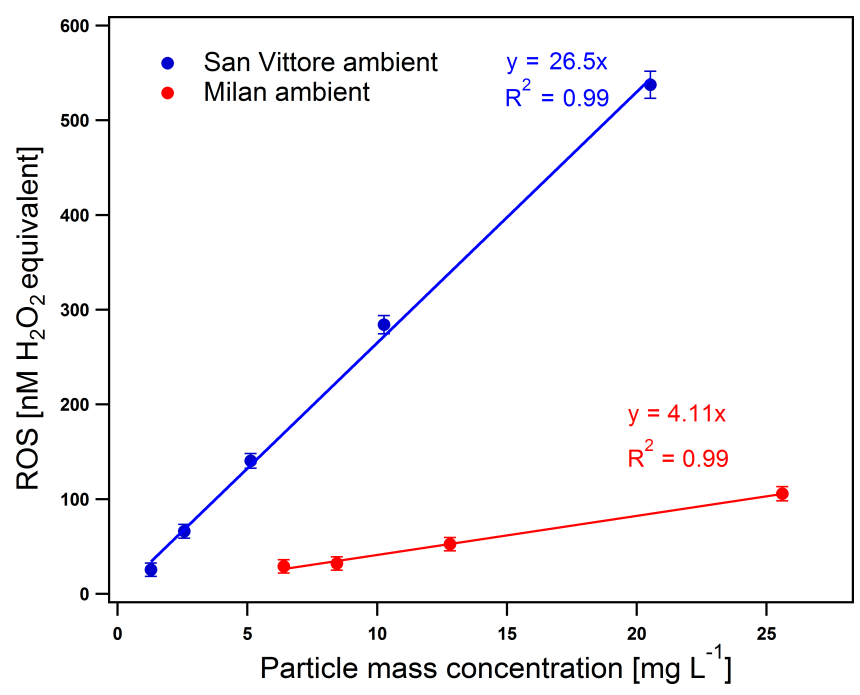

Figure 4. ROS content vs. dissolved particle mass concentration. Blue symbols represent $\mathrm{PM}_{10}$ samples from San Vittore in winter (Switzerland), and red symbols represent TSP samples from Milan in autumn (Italy). The error bars represent the instrument precision (see Sect. 3.1.2).

tors ranged from $\sim 100$ to 200 . Experiments were conducted at -10 or $15^{\circ} \mathrm{C}$ and at a relative humidity of $\sim 50 \%$. After the characterization of the primary emissions, $d 9$-butanol (D9, $98 \%$, Cambridge Isotope Laboratories) was injected into the chamber to determine the $\mathrm{OH}$ exposure from its decay (Barmet et al., 2012). A continuous injection of nitrous acid (2.3-2.6 $\mathrm{L} \mathrm{min}^{-1}$ ) was used to create $\mathrm{OH}$ by photolysis. The chamber was then irradiated with UV light (40 lights, 90-100 W, Cleo Performance, Philips) for 4.5-6 h (Platt et al., 2013). Real-time characterization of the aerosols from the smog chamber was carried out throughout the experiment with the online ROS analyzer and a high-resolution time-offlight aerosol mass spectrometer (HR-ToF-AMS, Aerodyne Research Inc.).

The evolution of ROS measured by the online method is shown in Fig. 5 for one exemplary smog chamber aging experiment. Injection of the wood combustion emissions led to a primary organic aerosol (POA) concentration of $25 \mu \mathrm{g} \mathrm{m}^{-3}$ and $26 \mathrm{nmol} \mathrm{m}^{-3}$ of particulate ROS in the smog chamber. After the lights were switched on (referred to as "lights on"), secondary organic aerosol (SOA) was produced and total organic aerosol (OA) measured by AMS reached a maximum concentration $1 \mathrm{~h}$ later but then decreased because of higher wall loss than the SOA production rate. The ROS concentration increased concurrently with the increasing OA, indicating the formation of ROS by photochemical reactions induced by $\mathrm{OH}$ radicals, but then decreased faster than OA. When we sampled through a particle filter inserted upstream of the ROS online analyzer (pink areas), the ROS signal went to almost zero, which was considered as a measurement baseline during aging (Fig. 5a).
To investigate the influence of aging on ROS formation, SOA and secondary ROS (ROS formed during aging) were calculated by subtracting POA and primary ROS from the total OA and total ROS measured during lights on (Fig. 5b), respectively. Here the POA and primary ROS calculation was based on the assumption that they were not further oxidized after lights on and the wall loss rate was the same as for the inert tracer black carbon (BC). The content of ROS in SOA (represented by ROS/SOA) was in the range of 0.4$1.26 \mathrm{nmol} \mathrm{mg}^{-1}$ within the oxidant $\mathrm{OH}$ exposure range of $0-30 \times 10^{6}$ molec $\mathrm{m}^{-3} \mathrm{~h}$. Initially, aging resulted in a high ROS content in SOA, which then decreased strongly with increasing $\mathrm{OH}$ exposure (Fig. 5c). This decrease could be due to further oxidation or decay of particulate ROS, indicating that first-generation products from the volatile organic compounds (VOCs) oxidation might play a more important role in ROS formation than later-generation molecules.

\subsection{Gas-phase interference test}

We tested the potential interference of trace gases and aerosol components on the DCFH signal. In principle, at the applied sample flow rate, $99 \%$ of the trace gases should get removed by the denuder. Specifically, we assessed the removal efficiency of the denuder with respect to the most abundant oxidizing trace gases $\mathrm{O}_{3}$ and $\mathrm{NO}_{2}$. After exposing the denuder to $464 \mathrm{ppb}$ ozone for $\sim 5 \mathrm{~h}$, no increase in the background signal was observed (Table 2). An amount of $500 \mathrm{ppb} \mathrm{NO}_{2}$ showed no increase in the background signal even without the denuder. The results in Table 2 indicate that a newly regenerated denuder completely removes $\mathrm{O}_{3}$, making the denuder suitable for both smog chamber (usually $\sim 5 \mathrm{~h}$ aging per experiment) and ambient measurements (1 day replacement interval). Based on these results we assume that gaseous $\mathrm{H}_{2} \mathrm{O}_{2}$ is also completely removed. Further, we regularly checked the ROS blank by measuring particle-free air by switching a three-port valve and sampling through a particle filter (disposable filter units, Balston, UK) installed in another line.

\subsection{Particle-phase matrix effects}

\subsubsection{Particulate $\mathrm{SO}_{4}^{2-}$ and $\mathrm{NO}_{3}^{-}$}

Previous measurements of filters from Milan showed a clear correlation of ROS with the particulate $\mathrm{SO}_{4}^{2-}$ and $\mathrm{NO}_{3}^{-}$concentration (Perrone et al., 2016). During the investigated period, the average $\mathrm{SO}_{4}^{2-}$ and $\mathrm{NO}_{3}^{-}$concentrations in Milan were 4 and $\sim 5-10 \mu \mathrm{g} \mathrm{m}^{-3}$, respectively. Here, we investigate whether $\mathrm{SO}_{4}^{2-}$ and $\mathrm{NO}_{3}^{-}$exhibit a response in the DCFH assay. Therefore, we tested the fluorescence response to $\sim 1.38 \mu_{\mathrm{M} \mathrm{SO}_{4}^{2-}}^{2-}$ and $\sim 20 \mu \mathrm{M} \mathrm{NO}_{3}^{-}$solutions prepared from $\left(\mathrm{NH}_{4}\right)_{2} \mathrm{SO}_{4}$ and $\mathrm{NH}_{4} \mathrm{NO}_{3}$, respectively. Such concentrations would typically be observed after collection of $23.5 \mu \mathrm{g} \mathrm{m}^{-3}$ of $\mathrm{SO}_{4}^{2-}$ and $228 \mu \mathrm{g} \mathrm{m}^{-3}$ of $\mathrm{NO}_{3}^{-}$with the online instrument. This is equivalent to $\sim 5$ and $\sim 30$ times higher concentra- 


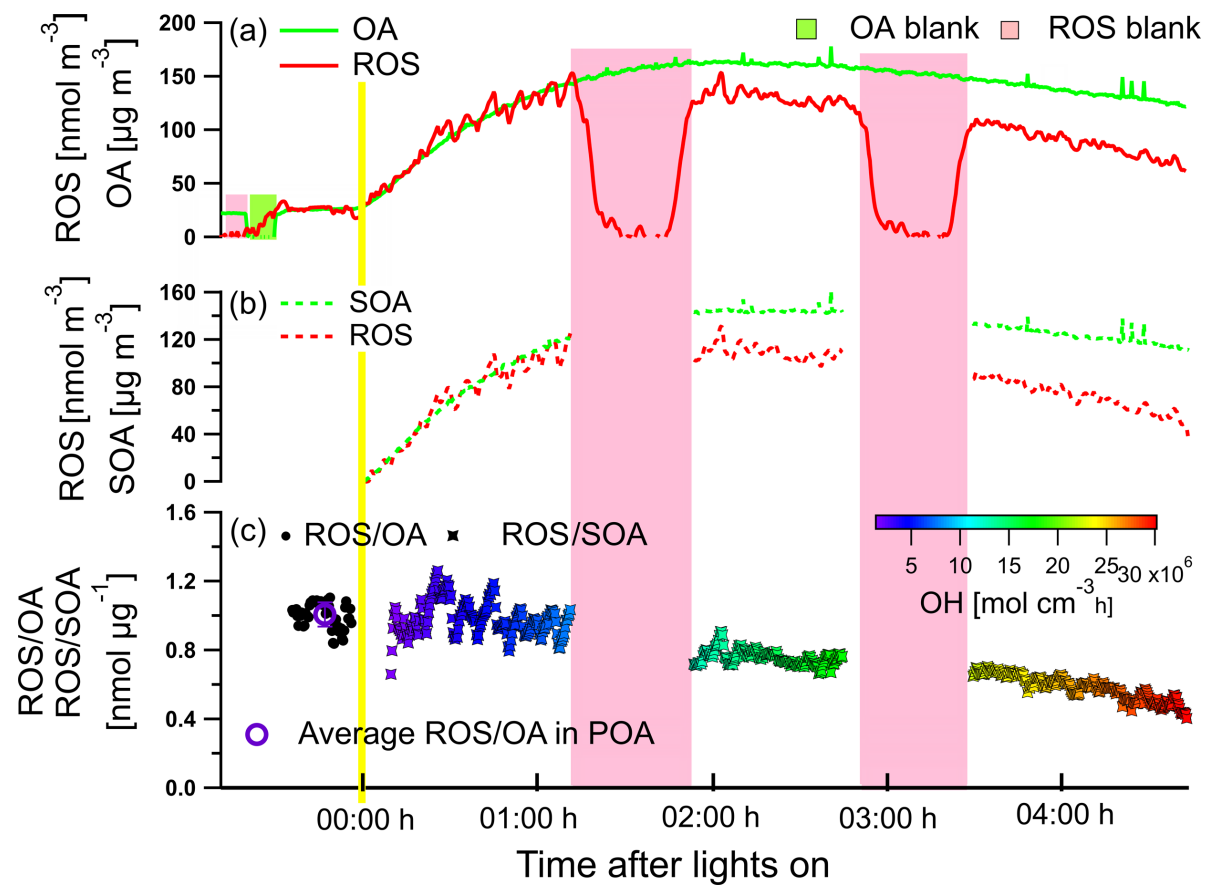

Figure 5. Evolution of the concentrations of OA mass and ROS during an online wood combustion smog chamber aging experiment. (a) Total OA and ROS, (b) SOA and ROS, (c) ROS content in the OA (before lights on) and ROS content in the SOA (after lights on) as a function of the $\mathrm{OH}$ dose.

Table 2. Effects of the potential interferences in the gas and aerosol phase on the DCFH signal.

\begin{tabular}{ll|ll|ll}
\hline \multicolumn{2}{c|}{ Species tested } & \multicolumn{1}{|c|}{ Concentration applied } & \multicolumn{2}{|c}{$\begin{array}{l}\text { Measured concentration } \\
\left(\mathrm{H}_{2} \mathrm{O}_{2} \text { eq. }\right.\end{array}$} \\
\hline \multirow{2}{*}{$\begin{array}{l}\text { without } \\
\text { denuder }\end{array}$} & $\begin{array}{l}\text { without } \\
\text { denuder }\end{array}$ & $\begin{array}{l}\text { with } \\
\text { denuder }\end{array}$ & $\begin{array}{l}\text { without } \\
\text { denuder }\end{array}$ & $\begin{array}{l}\text { with } \\
\text { denuder }\end{array}$ \\
\hline Gas phase & $\mathrm{O}_{3}$ & $464 \mathrm{ppb}$ & $464 \mathrm{ppb}^{*}$ & $150 \mathrm{nM}$ & $0 \mathrm{nM}$ \\
& $\mathrm{NO}_{2}$ & $500 \mathrm{ppb}$ & - & $0 \mathrm{nM}$ & - \\
\hline Particle & $\mathrm{SO}_{4}^{2-}$ & $23.5 \mu \mathrm{g} \mathrm{m}^{-3}$ & - & $-4.8 \mathrm{nM}$ & - \\
phase & $\mathrm{NO}_{3}^{-}$ & $228 \mu \mathrm{g} \mathrm{m}^{-3}$ & - & $-3.5 \mathrm{nM}$ & - \\
& $\mathrm{SO}_{4}^{2-}+\mathrm{H}_{2} \mathrm{O}_{2}$ & $23.5 \mu \mathrm{g} \mathrm{m}^{-3}+115 \mathrm{nM}$ & - & $105 \mathrm{nM}$ & - \\
& $\mathrm{NO}_{3}^{-}+\mathrm{H}_{2} \mathrm{O}_{2}$ & $228 \mu \mathrm{g} \mathrm{m}^{-3}+115 \mathrm{nM}$ & - & $110 \mathrm{nM}$ & - \\
& $\mathrm{SO}_{4}^{2-}+2-\mathrm{BP}$ & $23.5 \mu \mathrm{g} \mathrm{m}^{-3}+272.5 \mathrm{nM}$ & - & $272.5 \mathrm{nM}$ & - \\
\hline
\end{tabular}

* Denuder was exposed for $\sim 5 \mathrm{~h}$.

tions than observed in Milan (Perrone et al., 2016). These measurements are then compared to cross-sensitivity tests of $\sim 1.38 \mu \mathrm{M} \mathrm{SO}_{4}^{2-}$ and $\sim 20 \mu \mathrm{M} \mathrm{NO}_{3}^{-}$with $115 \mathrm{nM} \mathrm{H}_{2} \mathrm{O}_{2}$ and $272.5 \mathrm{nM}$ 2-BP (Table 2).

Results show that the signals generated by injecting $\left(\mathrm{NH}_{4}\right)_{2} \mathrm{SO}_{4}$ and $\mathrm{NH}_{4} \mathrm{NO}_{3}$ were on average lower than the instrument background by -4.8 and $-3.5 \mathrm{nM}\left(\mathrm{H}_{2} \mathrm{O}_{2}\right.$ eq. $)$, respectively. According to the reproducibility of the instrument background discussed in Sect. 3.1.1, these differences are not statistically significant. For the cross-sensitivity test, the fluorescence response of the $\mathrm{SO}_{4}^{2-}-\mathrm{H}_{2} \mathrm{O}_{2}$ mixture $\left(23.5 \mu \mathrm{g} \mathrm{m}^{-3} \mathrm{SO}_{4}^{2-}+115 \mathrm{nM} \mathrm{H}_{2} \mathrm{O}_{2}\right)$ and the $\mathrm{NO}_{3}^{-}-\mathrm{H}_{2} \mathrm{O}_{2}$ mixture $\left(228 \mu \mathrm{g} \mathrm{m}^{-3} \mathrm{NO}_{3}^{-}+115 \mathrm{nM} \mathrm{H}_{2} \mathrm{O}_{2}\right)$ corresponded on average to 105 and $110 \mathrm{nM} \mathrm{H}_{2} \mathrm{O}_{2}$ equivalent, respectively. These deviations from the value measured for $\mathrm{H}_{2} \mathrm{O}_{2}$ alone $(115 \mathrm{nM})$ are not statistically different from zero ( $z$ score test, $p$ value $\sim 0.7$ for $\mathrm{SO}_{4}^{2-}$ and $\mathrm{NO}_{3}^{-}$), within our measurement precision (Sect. 3.1.2). The $\mathrm{SO}_{4}^{2-}-2$ - $\mathrm{BP}$ mixture $\left(23.5 \mu \mathrm{g} \mathrm{m}^{-3} \mathrm{SO}_{4}^{2-}+272.5 \mathrm{nM} 2-\mathrm{BP}\right)$ also showed a similar result. We conclude from these tests that particulate $\mathrm{SO}_{4}^{2-}$ and $\mathrm{NO}_{3}^{-}$, the most abundant single particulate components, neither show any ROS signals nor influence the $\mathrm{H}_{2} \mathrm{O}_{2}$ and 2- 


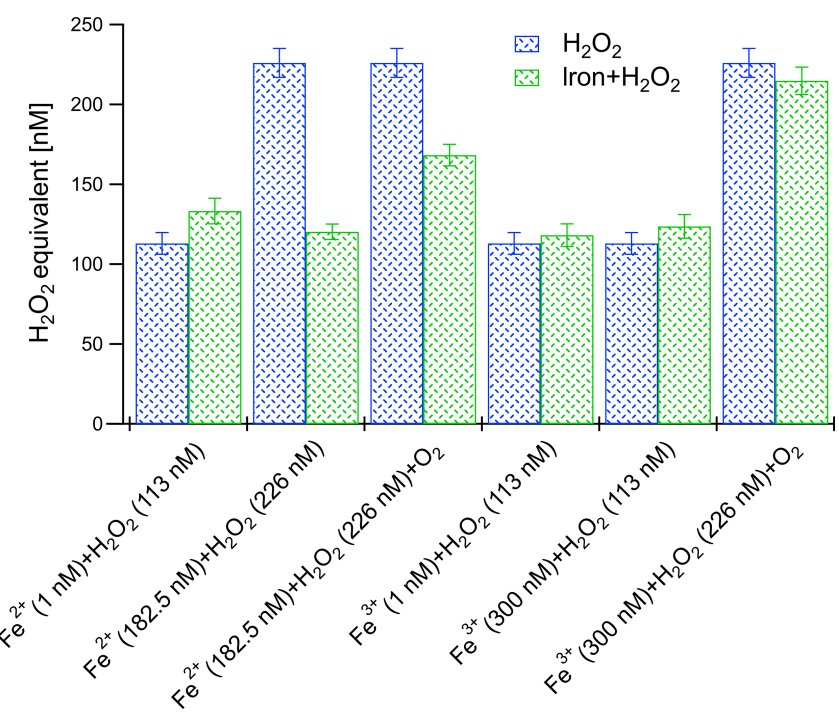

Figure 6. The relative fluorescence intensity during $\mathrm{Fe}^{2+}$ and $\mathrm{Fe}^{3+}$ cross-sensitivity tests with $\mathrm{H}_{2} \mathrm{O}_{2}$. The blue bars represent the premixed $\mathrm{H}_{2} \mathrm{O}_{2}$ concentrations, and the green bars represent the [iron $+\mathrm{H}_{2} \mathrm{O}_{2}$ ] mixture concentrations. The error bars were calculated based on the instrument precision (see Sect. 3.1.2).

BP measurements and that the observed relationship between the secondary species and the ROS signals in ambient air is rather a correlation and not based on causation.

\subsubsection{Transition metals}

Transition metals may induce a response through redox cycling. Iron is one of the most abundant transition metals in the aerosol (Valko et al., 2005; Dall'Osto et al., 2016). However, potential iron-catalyzed ROS formation in an oxygen-rich environment has not yet been examined using a DCFH assay. In order to investigate the effect of metals on the ROS signal we conducted two experiments: (1) the analysis of the $\mathrm{H}_{2} \mathrm{O}_{2}$ reaction with $\mathrm{DCFH}$ in the presence of $\mathrm{FeCl}_{2}$ (anhydrous, $99.998 \%$, Sigma-Aldrich, USA) and $\mathrm{FeCl}_{3}\left(\mathrm{FeCl}_{3} \cdot 6 \mathrm{H}_{2} \mathrm{O}\right.$, Sigma-Aldrich, USA) and (2) the analysis of the $\mathrm{H}_{2} \mathrm{O}_{2}$ signal in the presence of ambient aerosols extracted from filter samples.

In the first set of experiments (shown in Fig. 6) the signal of $\mathrm{H}_{2} \mathrm{O}_{2}$ measured alone was compared with that of a mixed $\mathrm{FeCl}_{2}-\mathrm{H}_{2} \mathrm{O}_{2}$ solution. At a concentration of $1 \mathrm{nM}$ soluble $\mathrm{Fe}^{2+}$ in water, no influence on the ROS signal was observed within a standard deviation. The same procedure was then applied to $\mathrm{H}_{2} \mathrm{O}_{2}(226 \mathrm{nM})$ combined with significantly higher $\mathrm{Fe}^{2+}$ concentrations $(182.5 \mathrm{nM})$. The fluorescence signals of the $\mathrm{Fe}^{2+}-\mathrm{H}_{2} \mathrm{O}_{2}$ mixture, both with and without the presence of dissolved $\mathrm{O}_{2}$, were significantly lower than the signal when measuring $\mathrm{H}_{2} \mathrm{O}_{2}$ alone. This might be due to the consumption of a substantial amount of $\mathrm{H}_{2} \mathrm{O}_{2}$ by $\mathrm{Fe}^{2+}$, for the production of $\mathrm{HO}\left(\mathrm{Fe}^{2+}+\mathrm{H}_{2} \mathrm{O}_{2} \rightarrow \mathrm{Fe}^{3+}+\mathrm{OH}^{-}+\mathrm{HO}\right)$, which will further react with $\mathrm{H}_{2} \mathrm{O}_{2}$ and result in the fur- ther reduction of the $\mathrm{H}_{2} \mathrm{O}_{2}$ concentration $\left(\mathrm{HO}+\mathrm{H}_{2} \mathrm{O}_{2} \rightarrow\right.$ $\mathrm{H}_{2} \mathrm{O}+\mathrm{HO}_{2} ; \mathrm{HO}_{2}+\mathrm{H}_{2} \mathrm{O}_{2} \rightarrow \mathrm{O}_{2}+\mathrm{H}_{2} \mathrm{O}+\mathrm{HO}$ ) (Kolthoff and Medalia, 1949). This indicates that concentrations of soluble $\mathrm{Fe}^{2+} \leq 1 \mathrm{nM}$, which were obtained at ambient concentrations of $\leq 10 \mathrm{ng} \mathrm{m}^{-3}$ soluble $\mathrm{Fe}^{2+}$ in the online instrument, will not influence the ROS measurement. However, in cases of high ambient soluble $\mathrm{Fe}^{2+}$ concentrations the ROS signal might be reduced, whereby this also depends on the $\mathrm{H}_{2} \mathrm{O}_{2}$ equivalent concentration. Measured ambient iron concentrations were found to be in the range of tens to several thousands of $\mathrm{ng} \mathrm{m}^{-3}$ (Perrone et al., 2016; Oakes et al., 2012; Visser et al., 2015). Oakes et al. (2012) reported that water-soluble $\mathrm{Fe}$ (II) constitutes between 2.5 and $32 \%$ of total iron, resulting in a water-soluble $\mathrm{Fe}(\mathrm{II})$ concentration up to $30 \mathrm{ng} \mathrm{m}^{-3}$, which would be equivalent to $\sim 2 \mathrm{nM}$ in our online instrument. According to our first pair of experiments in Fig. 6 ( $1 \mathrm{nM} \mathrm{Fe}^{2+}$ mixed with $113 \mathrm{nM} \mathrm{H}_{2} \mathrm{O}_{2}$ solution) this would not suppress the ROS signal. Meanwhile, the $\mathrm{H}_{2} \mathrm{O}_{2}-$ $\mathrm{Fe}^{3+}$ mixture signal was observed to be almost the same as the $\mathrm{H}_{2} \mathrm{O}_{2}$ signal alone with and without the presence of $\mathrm{O}_{2}$, which is in agreement with the findings of LeBel et al. (1992) and Keenan et al. (2009). These findings were further evaluated below by examining the influence of genuine atmospheric particulate metals on the $\mathrm{H}_{2} \mathrm{O}_{2}$ signal.

We then investigated whether the complex matrix of ambient particles, which also include different forms of iron together with other metals, has an influence on ROS measurements. For this second set of experiments, ambient filter samples from a rural site in San Vittore (Switzerland) collected in January 2013 and an urban site located in Bern (Switzerland) collected in November 2014 were extracted and cross tested with $\mathrm{H}_{2} \mathrm{O}_{2}$. In San Vittore, three concentrations of $\mathrm{PM}_{10}$ from one filter punch were prepared, while in Bern three concentrations of $\mathrm{PM}_{2.5}$ from three different filters were prepared. Figure 7 compares the fluorescence response of the filter-extract- $\mathrm{H}_{2} \mathrm{O}_{2}$ mixture with the sum of the separately measured signals of the filter extract and of the $\mathrm{H}_{2} \mathrm{O}_{2}$. To account for the large differences in PM concentrations the signals were normalized to the signal of the filter extract. Results from both San Vittore and Bern lie on the $1: 1$ line within our errors. This indicates that at concentrations relevant for the ambient atmosphere the complex matrix of ambient particles has no influence on ROS signals.

\subsection{Assessment of ROS stability}

\subsubsection{Comparison of online and offline measurements}

A direct intercomparison of online in situ and offline filter sample measurements of the ROS content from different emission sources was performed. These aerosol samples included fresh and aged aerosols from wood combustion emissions from a smog chamber, as well as ambient aerosols collected in Bern (Switzerland). 


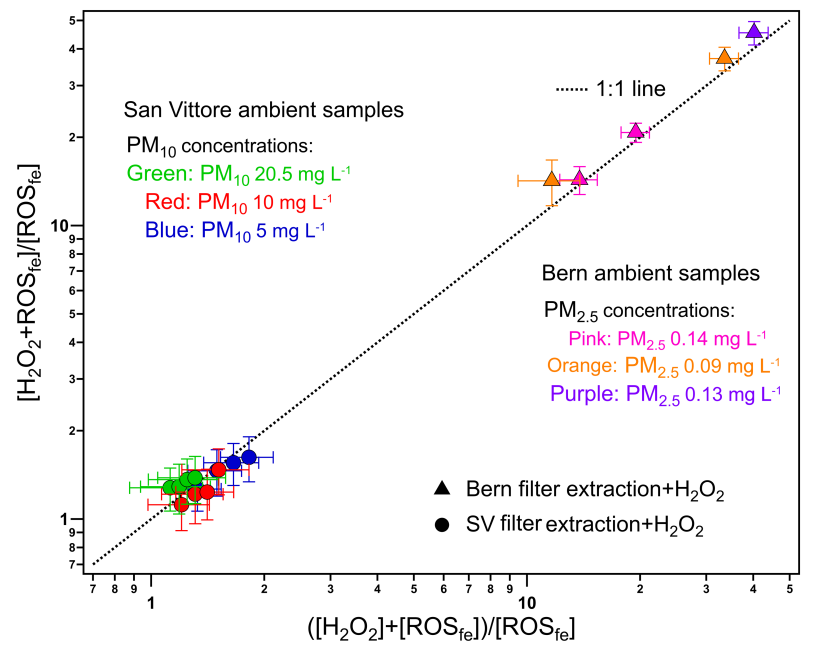

Figure 7. Comparison of the filter extract (fe)- $\mathrm{H}_{2} \mathrm{O}_{2}$ mixture with the sum of the separately measured filter extract and $\mathrm{H}_{2} \mathrm{O}_{2}$ response, both normalized to the filter extract signal. $\left[\mathrm{H}_{2} \mathrm{O}_{2}+\mathrm{ROS}_{\mathrm{fe}}\right]$ represents the fluorescence response of the filter-extract- $\mathrm{H}_{2} \mathrm{O}_{2}$ mixture; $\left[\mathrm{H}_{2} \mathrm{O}_{2}\right]$ and $\left[\mathrm{ROS}_{\mathrm{fe}}\right]$ represent the fluorescence response of $\mathrm{H}_{2} \mathrm{O}_{2}$ and the filter extracts alone. The symbols represent different locations of the samples collected. The colors represent different PM concentrations based on the mass on the filter punch and assuming $100 \%$ water solubility. $\mathrm{H}_{2} \mathrm{O}_{2}$ concentrations mixed together with each PM concentration ranged from 56.5 to $113 \mathrm{nM}$ and from 40 to $100 \mathrm{nM}$ in Bern and San Vittore, respectively, which are also indicated indirectly on the $x$ and $y$ axes. Error bars represent the propagated uncertainty from the measurements of $\left[\mathrm{H}_{2} \mathrm{O}_{2}+\mathrm{ROS}_{\mathrm{fe}}\right]$, $\left[\mathrm{ROS}_{\mathrm{fe}}\right]$ and $\left[\mathrm{H}_{2} \mathrm{O}_{2}\right]$.

The smog chamber experiments and the online performance were described in Sect. 3.1.3. In addition to the online measurements, the particles from the chamber were collected on quartz filters $(47 \mathrm{~mm}$, Pall Corporation) at a flow rate of $26 \mathrm{~L} \mathrm{~min}^{-1}$ for 30-32 min behind a charcoal denuder to remove organic vapors. Primary particles were collected after injection of the emissions into the smog chamber and before the lights were turned on. Aged particles were collected after around 1 and $4 \mathrm{~h}$ of aging. The filters were immediately stored at $253 \mathrm{~K}$ and analyzed $\sim 2$ years after the smog chamber experiments.

Ambient measurements were performed at an urban site located at the Institute of Anatomy of the University of Bern. A stainless steel cyclone (URG-2000-30ET, URG Corporation) was operated at a constant flow rate of $\sim 100 \mathrm{~L} \mathrm{~min}^{-1}$ to select particulate matter with an aerodynamic diameter $<2.5 \mu \mathrm{m}$. After size selection, particles were enriched using a versatile aerosol concentration enrichment system (VACES) (Kim, et al., 2001) and dried by passing through a diffusion dryer. Organic vapors were removed from the airstream using a charcoal denuder. The physicochemical properties of the aerosols were characterized using the online ROS analyzer, a scanning mobility particle sizer (SMPS, custom built) and a quadrupole aerosol chemical speciation monitor (ACSM, Aerodyne Research Inc.) for the measurement of the nonrefractory aerosol composition. Particle-bound ROS were always measured downstream of the VACES due to the low ambient aerosol concentration while the other instruments measured ambient air most of the time. For offline quantification of particle-bound ROS, particles were periodically collected either up- or downstream of the VACES on Teflon filters $(47 \mathrm{~mm}$ Fluoropore membrane, $3.0 \mu \mathrm{m}$ pore size, Merck Millipore, Molsheim, France) for at least $2 \mathrm{~h}$. Prior to deposition on the filter, the sample flow was passed through a charcoal denuder removing oxidizing and organic gases. Sampling time was $3 \mathrm{~h}$ and filters were immediately stored at $-20^{\circ} \mathrm{C}$. Filter punches were then extracted as described in Sect. 2.1.3 and analyzed for the ROS content $\sim 1$ year after sampling.

The ROS concentrations measured by the online and offline method from the wood combustion experiments and ambient air in Bern are compared in Fig. 8. We did not observe a systematic difference between ROS concentrations on filters taken before and after the VACES compared with the online measurements. The ROS concentrations measured offline are on average $31 \%$ lower than the online data in the Bern ambient measurements and on average 67 and $61 \%$ lower than the online data for primary and secondary wood combustion samples, respectively. For the ambient measurements in Bern, a small number of measurements show agreement between the two methods indicating no ROS decay. A more detailed analysis is given in the following section to further explain the discrepancies of offline and online measurements.

\subsubsection{ROS degradation}

As ROS decay with time, we investigated the evolution of the particle-bound ROS over time by measuring ROS from filter samples taken during additional biomass combustion laboratory experiments. The temperature of the filter samples was maintained at $-20^{\circ} \mathrm{C}$, except during transport which lasted $\sim 3 \mathrm{~h}$ where the samples were packed at $0^{\circ} \mathrm{C}$ using ice packs. As this might have an additional effect on the results, ROS lifetimes determined at $-20^{\circ} \mathrm{C}$ should be considered as the lowest estimates.

A pellet boiler was operated under two different conditions: high excess of combustion air $\left(\lambda^{++}\right)$and lack of combustion air $\left(\lambda^{-}\right)$(see Table 3 ). The emissions from the pellet boiler were sampled from the chimney through a heated line $(473 \mathrm{~K})$ and diluted by a factor of $\sim 100-150$ using two ejector diluters in series (VKL10, Palas $\mathrm{GmbH}$ ). The emissions were then aged in a PAM chamber to simulate photochemical aging of the emissions and assess the potential of secondary organic aerosol (SOA) formation. The design and the use of the PAM chamber is described by Kang et al. (2007) and Bruns et al. (2015). Gas-phase $\mathrm{O}_{2}$ and $\mathrm{CO}$ (using a paramagnetic oxygen analyzer for $\mathrm{O}_{2}$ and a non-dispersive in- 
Table 3. Short-lived and long-lived ROS fractions and parameters from the different experiments (Ex $n$ denotes the number of the experiment)

\begin{tabular}{|c|c|c|c|c|c|c|}
\hline Filter & Ex1 & Ex2 & Ex3 & Ex4 & Ex5 & Ex6 \\
\hline$\lambda^{1}$ & $1.31\left(\lambda^{-}\right)$ & $3.25\left(\lambda^{++}\right)$ & $3.33\left(\lambda^{++}\right)$ & $3.18\left(\lambda^{++}\right)$ & $3.16\left(\lambda^{++}\right)$ & $3.36\left(\lambda^{++}\right)$ \\
\hline $\mathrm{MCE}^{6}$ & 0.99 & 0.98 & 0.97 & 0.98 & 0.98 & 0.96 \\
\hline$T$ (chamber, $\left.{ }^{\circ} \mathrm{C}\right)$ & 37.9 & 37.9 & 37.9 & 39.8 & 39.8 & 39.8 \\
\hline RH (chamber, \%) & 18.6 & 24 & 24.5 & 20.9 & 20.9 & 20.9 \\
\hline $\mathrm{OA}^{2}\left(\mu \mathrm{g} \mathrm{m}^{-3}\right)$ & 43.0 & 39.1 & 29.0 & 4.5 & 9.9 & 16.5 \\
\hline $\mathrm{CH}_{4}^{4,5}$ (ppmv, norm) & 0.017 & 0.16 & 0.16 & 0.027 & 0.087 & 0.13 \\
\hline $\mathrm{CO}^{4,5}$ (ppmv, norm) & 2.2 & 11.0 & 11.5 & 4.5 & 6.3 & 8.6 \\
\hline $\mathrm{CO}_{2}^{3,4,5}$ (ppmv, norm) & 375.5 & 391.5 & 381.1 & 210.8 & 212.13 & 203.0 \\
\hline $\mathrm{NMVOCs}^{4,5,7}$ (ppm, norm) & 0.04 & 0.74 & 0.78 & 0.13 & 0.45 & 0.6 \\
\hline Long-lived fraction $\left(A_{2}\right)$ & $29.3 \pm 2.5 \%$ & $58.4 \pm 10.6 \%$ & $59.3 \pm 12.6 \%$ & $24.5 \pm 3.7 \%$ & $100 \pm 17.6 \%$ & $90.8 \pm 13.6 \%$ \\
\hline
\end{tabular}

\footnotetext{
${ }^{1}$ Air fuel equivalence ratio $(\lambda) \cdot \lambda=O_{2, \text { amb }}[\%] /\left(\mathrm{O}_{2, \text { amb }}[\%]-\mathrm{O}_{2, \text { exh }}[\%]\right)$, where $\mathrm{O}_{2, \text { amb }}$ and $\mathrm{O}_{2, \text { exh }}$ are the oxygen contents in ambient air $\left(O_{2}\right.$,amb $\left.=21 \%\right)$ and the one measured in the flue gas, respectively. ${ }^{2} \mathrm{OA}=$ primary $\mathrm{OA}+$ secondary OA. ${ }^{3}$ Background corrected values. ${ }^{4}$ All the concentrations of gas- and particle-phase compounds are after the PAM. ${ }^{5}$ Norm indicates that concentrations are reported at $0{ }^{\circ} \mathrm{C}$ and $1013 \mathrm{mbar}$ and normalized to a reference $\mathrm{O}_{2}$ content of $13 \%$, $x_{\text {norm }}=[$ species $x] \times \lambda_{\text {actual }} / \lambda_{\text {reference }}{ }^{6} \mathrm{MCE}=\left[\mathrm{CO}_{2}\right] /\left(\left[\mathrm{CO}_{2}\right]+[\mathrm{CO}]\right)\left(\right.$ Ward and Radke, 1993). ${ }^{7}$ Non-methane VOCs $(\mathrm{NMVOCs})=\mathrm{VOC}-\mathrm{CH} 4$.
}

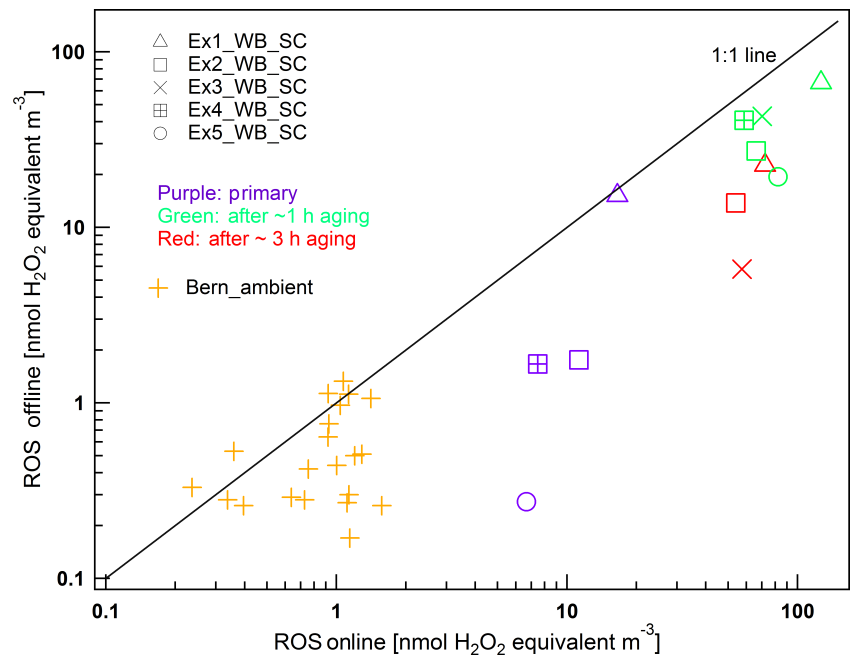

Figure 8. Comparison of online and offline measured ROS concentrations in the city of Bern in winter and during wood combustion smog chamber experiments (Ex $n \_$WB_SC), including primary aerosol samples (purple) and secondary aerosol samples after aging for $\sim 1$ (green) and $\sim 4 \mathrm{~h}$ (red). A deviation from the $1: 1$ line indicates a discrepancy between the online and offline method. Filters from the wood combustion experiments were analyzed 2 years after sampling, and those from ambient measurements were measured 1 year later.

frared, NDIR, analyzer for CO; Ultramat 23, Siemens), $\mathrm{CO}_{2}$ (NDIR analyzer, model LI-820, LI-COR ${ }^{\circledR}$ ), as well as total volatile organic compounds, and $\mathrm{CH}_{4}$ (using a flame ionization detector with a non-methane cutter; model 109A, J.U.M Engineering) were monitored in the hot, undiluted flue gas. In addition, non-methane volatile organic compounds (NMVOCs) as well as the OA, nitrate, ammonium and sulfate were measured after dilution using a proton transfer reaction mass spectrometer (PTR-MS, Ionicon) and a HR-ToF-AMS.
Aerosol filter samples were taken for $\sim 30 \mathrm{~min}$ on Teflon filters $(47 \mathrm{~mm}$ Fluoropore membrane, $3.0 \mu \mathrm{m}$ pore size, Merck Millipore) after the PAM chamber for ROS offline analyses. The filters were stored in the freezer from hours up to 4 months before the measurements of the ROS activity using the offline ROS setup (see Sect. 2.1.3).

The measured ROS concentrations in SOA from the different wood combustion experiments exhibit a clear decrease with increasing filter storage duration (Fig. 9). In addition, this decay seems to follow a double exponential function. This indicates the presence of a short-lived fraction $A_{1}$ with a decay constant $\pi_{1}=\ln (2) / T_{1}$ and a long-lived fraction $A_{2}$ with a decay constant $\pi_{2}=\ln (2) / T_{2}$, where $T_{i}$ represents the half-life. A biexponential decay function was applied to fit the experimental values, whereby the two decay constants are considered to be the same for all experiments:

$$
\begin{gathered}
\operatorname{ROS}_{\text {norm }}(t)=A_{1} \cdot \operatorname{EXP}\left(-\pi_{1} \cdot\left(t-t_{1}\right)\right) \\
+A_{2} \cdot \operatorname{EXP}\left(-\pi_{2} \cdot\left(t-t_{1}\right)\right) .
\end{gathered}
$$

Here $A_{2, i}=1-A_{1, i}, 0 \leq A_{1, i}, A_{2, i} \leq 1$, where $i$ refers to an experiment number; $t$ is the time after sampling; and $t_{1}$ is the time when the first offline measurement was performed. $\operatorname{ROS}_{\text {norm }}(t)$ is the ROS measured at time $t$ normalized to the ROS measured at time $t_{1}$. The model parameters and their respective uncertainties are shown in Table 3. Measured and modeled values are compared in Fig. 9.

The results show that the two ROS fractions have highly different reactivity. The final modeling yields $\pi_{1}=9.68 \pm 2.56$ and $\pi_{2}=0.0016 \pm 0.0019$. The second fraction (long lived) appears to be not reactive within our uncertainties and experimental timescales, as the associated reaction rate, $\pi_{2}$, is not statistically different from 0 . The first fraction (short lived) is highly reactive, with a halflife $T_{1} \approx 1.7 \pm 0.4 \mathrm{~h}$; similar reaction timescales and extents were observed for SOA from $\alpha$-pinene ozonolysis (Krapf et 


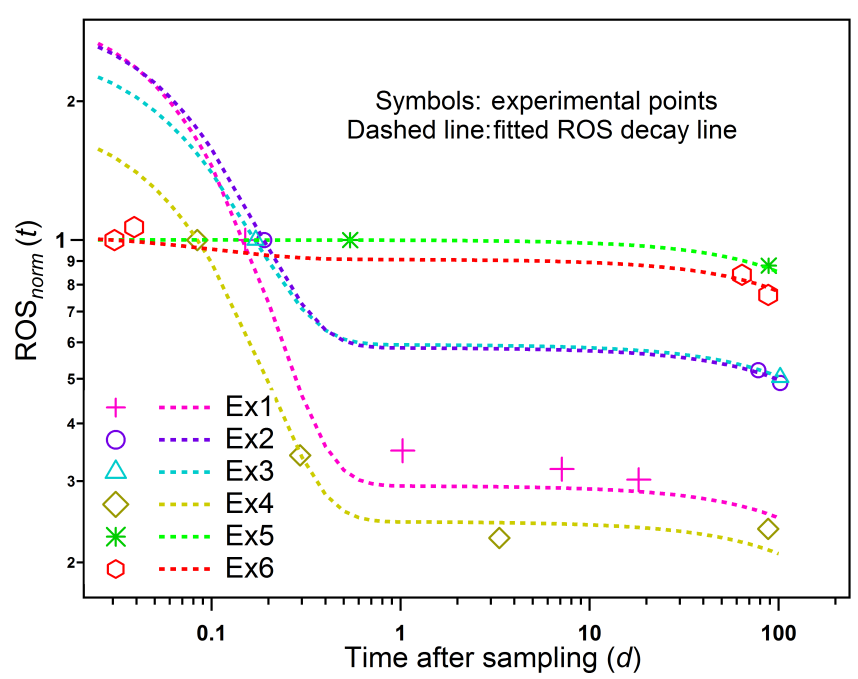

Figure 9. Measured and modeled ROS decays in SOA from wood combustion emissions with increasing sample storage duration for six experiments $(\mathrm{Ex} n)$. The symbols and dashed lines represent measured and modeled values, respectively. $\operatorname{ROS}_{\text {norm }}(t)$ is the ROS measured at time $t$ normalized to the ROS measured when the first offline measurement was performed at time $t_{1}$. More information about the experiments can be found in Table 3 . The very good agreement between measured and modeled ROS can be seen in Fig. S4.

al., 2016). The uncertainty analysis suggests that we are capable of determining the reaction rate of reactive ROS, but not that of the long-lived ROS. The fraction of the long-lived ROS $\left(A_{2, i}\right)$ could be determined with acceptable errors of $20 \%$. The main aim of the model is to show that the fraction of unstable ROS may vary significantly between experiments but could be as high as $75 \%$, which highlights the need for an online ROS measurement technique. This variability in the contribution of the unstable ROS fraction could be related to the burning conditions in this study (shown in Fig. S5).

The model considers ROS to be composed of two components with different decay rates. However, we do expect that the OA contains the spectrum of ROS with a wide range of reactivities. The model is thus a simplification of the ROS in the aerosol. Another simplification is that the decay rates of these two ROS components are considered to be the same between experiments. This may explain the reasons behind the high uncertainties in determining the rates, but does not have a significant effect on the determination of the contributions of the two fractions, $A_{1, i}$ and $A_{2, i}$. We also note that the decay rates and the ROS fractions determined from our results are specific for biomass burning SOA and cannot be extrapolated to other systems.

To understand the variability in the contributions of the long-lived and unstable ROS fractions of different experiments, the long-lived fraction of ROS was compared with various wood combustion parameters. No correlation was found with $\lambda, \mathrm{CO}, \mathrm{CO}_{2}$ and NMVOCs (defined in Table 3) nor with specific gas-phase families, e.g., polycyclic aromatic hydrocarbons, furans, oxygenated aromatics, and $\mathrm{N}$ containing or O-containing compounds. However, as shown in Fig. S5 the fraction of long-lived ROS seems to be negatively correlated with the modified combustion efficiency (MCE) and the total OA mass present in the chamber (with Ex4 as an exception). These results might indicate that the composition of ROS formed from photo-oxidation of wood combustion emissions depends on the combustion conditions. As semivolatile organic compounds have a higher chance to condense to the particle phase with increasing OA concentration, the anticorrelation of the long-lived fraction of ROS with OA concentration suggests that the more oxidized and low-volatility ROS tend to have longer lifetimes than the less oxidized and higher-volatility ROS. However, this would be in contradiction to Krapf et al. (2016), who concluded the highly oxygenated compounds to be unstable. The results presented here are preliminary and need to be further evaluated by more experiments.

Estimations of ROS lifetimes were done previously. ROS measured in oxidized oleic acid particles were separated into short- and long-lived species with a half-life of a few minutes and hours to days, respectively (Fuller et al., 2014). Chen et al. (2011) determined a ROS half-life of $6.5 \mathrm{~h}$ in oxidized organic aerosols. Krapf et al. (2016) showed that more than $60 \%$ of peroxides contained in SOA from $\alpha$-pinene ozonolysis decayed with a short half-life of $45 \mathrm{~min}$.

To compare the ROS online measurement with immediate offline measurements, 2,6-dimethoxyphenol was used as a precursor and aged in the PAM chamber. SOA was then sampled on a Teflon filter (47 mm Fluoropore membrane, $3.0 \mu \mathrm{m}$ pore size, Merck Millipore) at a flow rate of $1.7 \mathrm{~L} \mathrm{~min}^{-1}$ for $\sim 1 \mathrm{~h}$ after passing through a similar charcoal denuder as applied for the online measurements. The filter was then measured directly after sampling. Results showed that the offline measurement was $40 \%$ lower than the online measurement, indicating that already without significant sample storage duration the short-lived ROS fraction was lost in the offline methodology. This is in agreement with Fuller et al. (2014) and Krapf et al. (2016), who showed that a larger fraction of ROS in fresh SOA decays within tens of minutes.

As a summary of the ROS decay behavior in aerosols from Bern ambient and wood combustion experiments, a normalized frequency distribution of the ROS decay percentage of different sources is plotted in Fig. S6. The decay percentage of ROS was calculated as follows:

$\operatorname{ROS}_{\text {decay percentage }}=\left[\frac{\mathrm{ROS}_{\text {online }}-\mathrm{ROS}_{\text {offline }}}{\mathrm{ROS}_{\text {online }}}\right] \times 100 \%$.

The normalized frequency of a specified ROS decay percentage was then calculated as the ratio of the number of experiments yielding a certain decay percentage normalized to the number of total experiments. From Fig. S6 we conclude that the most frequently occurring ROS decay percentages were $40-80 \%$ in wood combustion experiments, whereby aging 
in the smog chamber and PAM chamber yielded similar results. Similarly, around $60 \%$ of ROS decayed in the majority of all the 27 ambient samples collected in Bern. Overall, the offline method underestimates the ROS content due to the degradation of short-lived ROS prior to filter analysis. The comparison of online and offline ROS measurements from ambient and wood combustion smog chamber experiments indicates that on average $60 \pm 20 \%$ of ROS decayed during filter storage and handling, highlighting the importance of online measurements.

\section{Conclusions}

In this study, a modified online and offline ROS analyzer was presented and characterized. The major improvements compared to previous studies (Fuller et al., 2014; Huang et al., 2016; Wang et al., 2011; King et al., 2013) to optimize the analysis were as follows: (1) degassing of the water and PBS to prepare the working solutions; (2) separation of DCFH and peroxidase working solutions, which were then mixed just before reaction with the sample solution; and (3) no ultrasonic filter extraction for offline analysis. All these efforts resulted in an instrument LOD of $2 \mathrm{nmol} \mathrm{m}^{-3}$ and $1.3 \mathrm{nmol} \mathrm{L}^{-1}$ for online and offline analysis, respectively. The method LOD of the offline analysis was $18 \mathrm{nmol} \mathrm{L}^{-1}$ based on the variability of the filter blanks and preparation of the solutions, respectively. The online instrument accuracy in determining the ROS concentration was found to be $3 \%$, and the instrument precision (repeatability) was 25,10 and $5 \%$ at 30,70 and $150 \mathrm{nM}$, respectively. The reproducibility of the instrument sensitivity was $\sim 40 \%$ due to solution preparation and instrument operation; thus, a calibration is needed for each experiment and new batch of WS.

As shown with model organic compounds only peracetic acid was quantitatively measured, while large organic peroxides or those with bulky functional groups (i.e., tert-butyl and phenyl) strongly reduced the fluorescence response of the DCFH assay. Potential interferences from gas-phase $\mathrm{O}_{3}$ and $\mathrm{NO}_{2}$ were not observed and matrix effects of particulate $\mathrm{SO}_{4}^{2-}$ and $\mathrm{NO}_{3}^{-}$were not statistically significant. While $\mathrm{Fe}^{3+}$ does not show a detectable interference, high soluble $\mathrm{Fe}^{2+}$ concentrations present in ambient aerosol could reduce the ROS signal.

Both online and offline measurements with the analyzer were performed in field and laboratory experiments. ROS concentrations from offline field measurements showed a linear relationship with increasing ambient particle concentrations. Smog chamber aging experiments of wood combustion emissions revealed a high initial ROS content in SOA, which then strongly decreased with $\mathrm{OH}$ exposure. Generally, ROS decayed with increasing filter storage duration. Due to the degradation of the highly reactive ROS fraction, the offline method generally underestimates the ROS concentration on average by $60 \pm 20 \%$. From the decay behavior, ROS in SOA can be separated into two categories: a short-lived or highly reactive fraction with a half-life of $\sim 1.7 \mathrm{~h}$ and longlived or less reactive species. Consequently, to obtain a better estimate of the real ROS concentration in the ambient air or in simulation chamber experiments, a fast online method as presented in this study is advantageous.

Data availability. Data related to this article are available online at https://zenodo.org/record/1118968\#WjkuTk2WxmM.

\section{The Supplement related to this article is available online at https://doi.org/10.5194/amt-11-65-2018-supplement.}

Competing interests. The authors declare that they have no conflict of interest.

Acknowledgements. This study was financially supported by the Swiss National Science Foundation (NRP 70 "Energy Turnaround") and the China Scholarship Council (CSC) under grant agreement no. 201007040040. The research leading to these results also received funding from the European Community's Seventh Framework Programme (FP7/2007-2013) under grant agreement no. 290605 (PSI-FELLOW) and from the Competence Center Environment and Sustainability (CCES; project OPTIWARES). The authors thank Maria Grazia Perrone and Manuel Krapf for providing the ambient filters, Mao Xiao for the helpful discussions, and René Richter and Günther Wehrle for their competent technical advice, as well as Samuel Brown, Ilaria Gavarini, Laure-Estelle Cassagnes and Deepika Bhattu for their support in the lab.

Edited by: Francis Pope

Reviewed by: two anonymous referees

\section{References}

Berglund, G. I., Carlsson, G. H., Smith, A. T., Szoke, H., Henriksen, A., and Hajdu, J.: The catalytic pathway of horseradish peroxidase at high resolution, Nature, 417, 463-468, 2002.

Bruns, E. A., El Haddad, I., Keller, A., Klein, F., Kumar, N. K., Pieber, S. M., Corbin, J. C., Slowik, J. G., Brune, W. H., Baltensperger, U., and Prévôt, A. S. H.: Inter-comparison of laboratory smog chamber and flow reactor systems on organic aerosol yield and composition, Atmos. Meas. Tech., 8, 23152332, https://doi.org/10.5194/amt-8-2315-2015, 2015.

Bruns, E. A., El Haddad, I., Slowik, J. G., Kilic, D., Klein, F., Baltensperger, U., and Prévôt, A. S. H.: Identification of significant precursor gases of secondary organic aerosols from residential wood combustion, Sci. Rep., 6, 27881, https://doi.org/10.1038/srep27881, 2016. 
Bruns, E. A., Slowik, J. G., El Haddad, I., Kilic, D., Klein, F., Dommen, J., Temime-Roussel, B., Marchand, N., Baltensperger, U., and Prévôt, A. S. H.: Characterization of gas-phase organics using proton transfer reaction time-of-flight mass spectrometry: fresh and aged residential wood combustion emissions, Atmos. Chem. Phys., 17, 705-720, https://doi.org/10.5194/acp-17-7052017, 2017.

Chen, X., Hopke, P. K., and Carter, W. P. L.: Secondary organic aerosol from ozonolysis of biogenic volatile organic compounds: Chamber studies of particle and reactive oxygen species formation, Environ. Sci. Technol., 45, 276-282, 2011.

Daellenbach, K. R., Stefenelli, G., Bozzetti, C., Vlachou, A., Fermo, P., Gonzalez, R., Piazzalunga, A., Colombi, C., Canonaco, F., Hueglin, C., Kasper-Giebl, A., Jaffrezo, J.-L., Bianchi, F., Slowik, J. G., Baltensperger, U., El-Haddad, I., and Prévôt, A. S. H.: Long-term chemical analysis and organic aerosol source apportionment at nine sites in central Europe: source identification and uncertainty assessment, Atmos. Chem. Phys., 17, 13265-13282, https://doi.org/10.5194/acp-17-132652017, 2017.

Dall'Osto, M., Beddows, D. C. S., Harrison, R. M., and Onat, B.: Fine iron aerosols are internally mixed with nitrate in the urban European atmosphere, Environ. Sci. Technol. 50, 4212-4220, 2016.

Deneke, S. M., Baxter, D. F., Phelps, D. T., and Fanburg, B. L.: Increase in endothelial cell glutathione and precursor amino acid uptake by diethyl maleate and hyperoxia, Am. J. Physiol., 257, https://doi.org/10.1152/ajplung.1989.257.4.L265, 1989.

Devasagayam, T. P., Tilak, J. C., Boloor, K. K., Sane, K. S., Ghaskadbi, S. S., and Lele, R. D.: Free radicals and antioxidants in human health: current status and future prospects, J. Assoc. Physician. I., 52, 794-804, 2004.

Donaldson, K., Brown, D., Clouter, A., Duffin, R., MacNee, W., Renwick, L., Tran, L., and Stone, V.: The pulmonary toxicology of ultrafine particles, J. Aerosol Med., 15, 213-220, 2002.

Fang, T., Verma, V., Guo, H., King, L. E., Edgerton, E. S., and Weber, R. J.: A semi-automated system for quantifying the oxidative potential of ambient particles in aqueous extracts using the dithiothreitol (DTT) assay: results from the Southeastern Center for Air Pollution and Epidemiology (SCAPE), Atmos. Meas. Tech., 8, 471-482, https://doi.org/10.5194/amt-8471-2015, 2015.

Fuller, S. J., Wragg, F. P. H., Nutter, J., and Kalberer, M.: Comparison of on-line and off-line methods to quantify reactive oxygen species (ROS) in atmospheric aerosols, Atmos. Environ., 92, 97$103,2014$.

Huang, W., Zhang, Y., Zhang, Y., Fang, D., and Schauer, J. J.: Optimization of the measurement of particle-bound reactive oxygen species with $2^{\prime}, 7^{\prime}$-dichlorofluorescin (DCFH), Water Air Soil Pollut., 227, 2016.

Ingham, D. B.: Diffusion of aerosols from a stream flowing through a cylindrical tube, J. Aerosol Sci., 6, 125-132, 1975.

Kang, E., Root, M. J., Toohey, D. W., and Brune, W. H.: Introducing the concept of Potential Aerosol Mass (PAM), Atmos. Chem. Phys., 7, 5727-5744, https://doi.org/10.5194/acp-7-5727-2007, 2007.

Kao, M. C. and Wang, C. S.: Reactive oxygen species in intense smoke, Aerosol Air Qual. Res., 2, 61-69, 2002.
Keenan, C. R., Goth-Goldstein, R., Lucas, D., and Sedlak, D. L.: Oxidative stress induced by zero-valent iron nanoparticles and $\mathrm{Fe}(\mathrm{II})$ in human bronchial epithelial cells, Environ. Sci. Technol., 43, 4555-4560, 2009.

Khurshid, S. S., Siegel, J. A., and Kinney, K. A.: Technical Note: Particulate reactive oxygen species concentrations and their association with environmental conditions in an urban, subtropical climate, Atmos. Chem. Phys., 14, 6777-6784, https://doi.org/10.5194/acp-14-6777-2014, 2014.

Kim, S., Jaques, P. A., Chang, M., Froines, J. R., and Sioutas, C.: Versatile aerosol concentration enrichment system (VACES) for simultaneous in vivo and in vitro evaluation of toxic effects of ultrafine, fine and coarse ambient particles Part I: Development and laboratory characterization, J. Aerosol Sci., 32, 1281-1297, 2001.

King, L. E. and Weber, R. J.: Development and testing of an online method to measure ambient fine particulate reactive oxygen species (ROS) based on the $2^{\prime}, 7^{\prime}$ dichlorofluorescin (DCFH) assay, Atmos. Meas. Tech., 6, 16471658, https://doi.org/10.5194/amt-6-1647-2013, 2013.

Kolthoff, I. M. and Medalia, A. I.: The reaction between ferrous iron and peroxides. I. reaction with hydrogen peroxide in the absence of oxygen, J. Am. Chem. Soc., 71, 3777-3783, 1949.

Krapf, M., Haddad, I. E., Bruns, E. A., Molteni, U., Daellenbach, K. R., Prévôt, A. S. H., Baltensperger, U., and Dommen, J.: Labile peroxides in secondary organic aerosol, Chem, 1, 603-616, 2016.

LeBel, C. P., Ischiropoulos, H., and Bondy, S. C.: Evaluation of the probe $2^{\prime}, 7^{\prime}$-dichlorofluorescin as an indicator of reactive oxygen species formation and oxidative stress, Chem. Res. Toxicol., 5, 227-231, 1992.

Long, G. L. and Winefordner, J. D.: Limit of detection a closer look at the IUPAC definition, Anal. Chem., 55, 712A-724A, 1983.

Mark, G., Tauber, A., Laupert, R., Schuchmann, H.-P., Schulz, D., Mues, A., and von Sonntag, C.: OH-radical formation by ultrasound in aqueous solution - Part II: Terephthalate and Fricke dosimetry and the influence of various conditions on the sonolytic yield, Ultrason. Sonochem., 5, 41-52, 1998.

Miljevic, B., Hedayat, F., Stevanovic, S., Fairfull-Smith, K. E., Bottle, S. E., and Ristovski, Z. D.: To sonicate or not to sonicate PM filters: Reactive oxygen species generation upon ultrasonic irradiation, Aerosol Sci. Technol., 48, 1276-1284, 2014.

Oakes, M., Weber, R. J., Lai, B., Russell, A., and Ingall, E. D.: Characterization of iron speciation in urban and rural single particles using XANES spectroscopy and micro X-ray fluorescence measurements: investigating the relationship between speciation and fractional iron solubility, Atmos. Chem. Phys., 12, 745-756, https://doi.org/10.5194/acp-12-745-2012, 2012.

Perrone, M. G., Zhou, J., Malandrino, M., Sangiorgi, G., Rizzi, C., Ferrero, L., Dommen, J., and Bolzacchini, E.: PM chemical composition and oxidative potential of the soluble fraction of particles at two sites in the urban area of Milan, Northern Italy, Atmos. Environ., 128, 104-113, 2016.

Pope, C. A. and Dockery, D. W.: Health effects of fine particulate air pollution: lines that connect, J. Air Waste Manage.Assoc., 56, 709-742, 2006.

Rota, C., Chignell, C. F., and Mason, R. P.: Evidence for free radical formation during the oxidation of $2^{\prime}-7^{\prime}$-dichlorofluorescin to the fluorescent dye $2^{\prime}-7^{\prime}$-dichlorofluorescein by horseradish peroxi- 
dase:: Possible implications for oxidative stress measurements, Free Radical Biol. Med., 27, 873-881, 1999a.

Rota, C., Fann, Y. C., and Mason, R. P.: Phenoxyl free radical formation during the oxidation of the fluorescent dye $2^{\prime}, 7^{\prime}$ dichlorofluorescein by horseradish peroxidase: possible consequences for oxidative stress measurements, J. Biol. Chem., 274, 28161-28168, 1999b.

Sagai, M., Saito, H., Ichinose, T., Kodama, M., and Mori, Y.: Biological effects of diesel exhaust particles - I. In vitro production of superoxide and in vivo toxicity in mouse, Free Radical Biol. Med., 14, 37-47, 1993.

Sauvain, J.-J., Rossi, M. J., and Riediker, M.: Comparison of three acellular tests for assessing the oxidation potential of nanomaterials, Aerosol Sci. Technol., 47, 218-227, 2013.

Takeuchi, M., Ullah, S. M. R., Dasgupta, P. K., Collins, D. R., and Williams, A.: Continuous collection of soluble atmospheric particles with a wetted hydrophilic Filter, Anal. Chem., 77, 80318040, 2005.

Valko, M., Morris, H., and Cronin, M. T. D.: Metals, Toxicity and oxidative stress, Curr. Med. Chem., 12, 1161-1208, 2005.

Venkatachari, P., Hopke, P. K., Brune, W. H., Ren, X., Lesher, R., Mao, J., and Mitchell, M.: Characterization of wintertime reactive oxygen species concentrations in Flushing, New York, Aerosol Sci. Technol., 41, 97-111, 2007.

Venkatachari, P., Hopke, P. K., Grover, B. D., and Eatough, D. J.: Measurement of particle-bound Reactive oxygen species in $\mathrm{Ru}-$ bidoux aerosols, J. Atmos. Chem., 50, 49-58, 2005.

Visser, S., Slowik, J. G., Furger, M., Zotter, P., Bukowiecki, N., Canonaco, F., Flechsig, U., Appel, K., Green, D. C., Tremper, A. H., Young, D. E., Williams, P. I., Allan, J. D., Coe, H., Williams, L. R., Mohr, C., Xu, L., Ng, N. L., Nemitz, E., Barlow, J. F., Halios, C. H., Fleming, Z. L., Baltensperger, U., and Prévôt, A. S. H.: Advanced source apportionment of size-resolved trace elements at multiple sites in London during winter, Atmos. Chem. Phys., 15, 11291-11309, https://doi.org/10.5194/acp-15-112912015, 2015.
Wang, Y., Hopke, P. K., Sun, L., Chalupa, D. C., and Utell, M. J.,: Laboratory and field testing of an automated atmospheric particle-bound reactive oxygen species sampling-analysis system, J. Toxicol., 2011, 419-476, 2011.

Ward, D. E. and Radke, L. F.: Emission measurements from vegetation fires: A comparative evalution of methods and results, in: Fire in the Environment: The Ecological, Atmospheric and Climatic Importance of Vegetation Fires, edited by: Crutzen, P. J. and Goldammer, J. G., John Wiley, Chichester UK, 1993.

WHO: Health Effects of Particulate Matter, Word Health Organization, Geneva, 2013.

Wragg, F. P. H., Fuller, S. J., Freshwater, R., Green, D. C., Kelly, F. J., and Kalberer, M.: An automated online instrument to quantify aerosol-bound reactive oxygen species (ROS) for ambient measurement and health-relevant aerosol studies, Atmos. Meas. Tech., 9, 4891-4900, https://doi.org/10.5194/amt-9-4891-2016, 2016.

Zhao, J. and Hopke, P. K.: Concentration of reactive oxygen species (ROS) in mainstream and sidestream cigarette smoke, Aerosol Sci. Technol., 46, 191-197, 2012.

Zhao, J. and Riediker, M.: Detecting the oxidative reactivity of nanoparticles: a new protocol for reducing artifacts, J. Nanopart. Res., 16, 2493, https://doi.org/10.1007/s11051-0142493-0, 2014.

Zotter, P., Ciobanu, V. G., Zhang, Y. L., El-Haddad, I., Macchia, M., Daellenbach, K. R., Salazar, G. A., Huang, R.-J., Wacker, L., Hueglin, C., Piazzalunga, A., Fermo, P., Schwikowski, M., Baltensperger, U., Szidat, S., and Prévôt, A. S. H.: Radiocarbon analysis of elemental and organic carbon in Switzerland during winter-smog episodes from 2008 to 2012 - Part 1: Source apportionment and spatial variability, Atmos. Chem. Phys., 14, 1355113570, https://doi.org/10.5194/acp-14-13551-2014, 2014. 